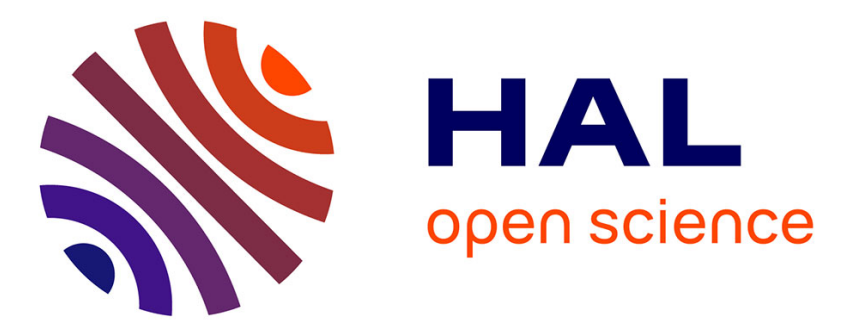

\title{
Accurate hydrogenated vegetable oil viscosity predictions for monolith reactor simulations
}

Pierre Albrand, Carine Julcour-Lebigue, Vincent Gerbaud, Anne-Marie Billet

\section{To cite this version:}

Pierre Albrand, Carine Julcour-Lebigue, Vincent Gerbaud, Anne-Marie Billet. Accurate hydrogenated vegetable oil viscosity predictions for monolith reactor simulations. Chemical Engineering Science, 2020, 214, pp.115388. 10.1016/j.ces.2019.115388 . hal-02735452

\section{HAL Id: hal-02735452 \\ https://hal.science/hal-02735452}

Submitted on 2 Jun 2020

HAL is a multi-disciplinary open access archive for the deposit and dissemination of scientific research documents, whether they are published or not. The documents may come from teaching and research institutions in France or abroad, or from public or private research centers.
L'archive ouverte pluridisciplinaire HAL, est destinée au dépôt et à la diffusion de documents scientifiques de niveau recherche, publiés ou non, émanant des établissements d'enseignement et de recherche français ou étrangers, des laboratoires publics ou privés. 


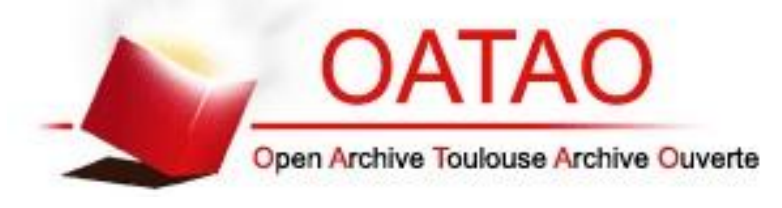

Open Archive Toulouse Archive Ouverte

OATAO is an open access repository that collects the work of Toulouse researchers and makes it freely available over the web where possible

This is an author's version published in: http://oatao.univ-toulouse.fr/25263

Official URL : https://doi.org/10.1016/..ces.2019.115388

\section{To cite this version:}

Albrand, Pierre Billet, Anne-Marie $\Rightarrow$ Accurate hydrogenated vegetable oil viscosity predictions for monolith reactor simulations. (2020) Chemical Engineering Science, 214. 115388. ISSN 0009-2509

Any correspondence concerning this service should be sent to the repository administrator: tech-oatao@listes-diff.inp-toulouse.fr 


\title{
Accurate hydrogenated vegetable oil viscosity predictions for monolith reactor simulations
}

\author{
Pierre Albrand, Carine Julcour, Vincent Gerbaud, Anne-Marie Billet* \\ Laboratoire de Génie Chimique, Université de Toulouse, CNRS, INPT, UPS, Toulouse, France
}

\section{H I G H L I G H T S}

- Contribution group model to predict viscosity of partially hydrogenated edible oils.

- CFD simulations of a three-phase catalytic monolith reactor with viscosity change.

- Investigation of two-way coupling between hydrodynamics, transport and reaction.

- Strong limitations by mass transfer of fatty acids highlighted.

- Reactor performances greatly impacted by the evolution of viscosity and diffusivity.

\section{Introduction}

World vegetable oil production was estimated to be 200 million tons in 2018 (George and Loeser, 2019). While the production of naturally saturated vegetable fats (such as palm oil) has increased by a factor 10 in the last 30 years, concerns regarding deforestation and carbon emissions induced by cultivation have been raised

\footnotetext{
* Corresponding author.

E-mail address: annemarie.billet@toulouse-inp.fr (A.-M. Billet).
}

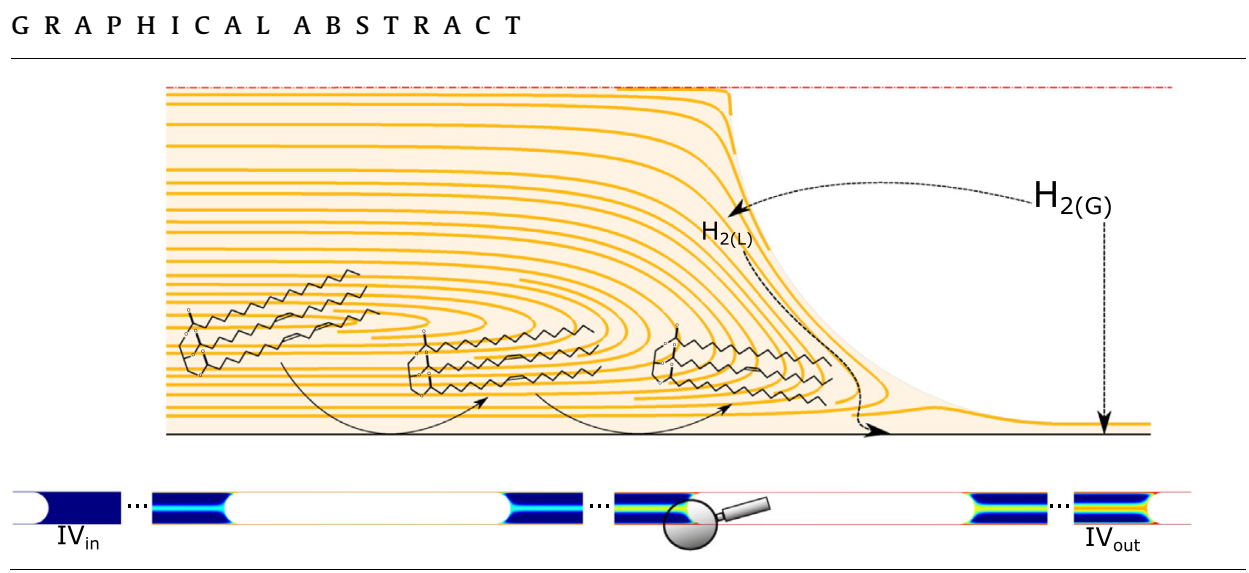

\begin{abstract}
A B S T R A C T
The viscosity of edible oils was measured before and after hydrogenation to assess a new model for predicting the viscosity of partially hydrogenated oils with given saturation degree and temperature. This contribution group model is based on a semi-predictive approach, and can be used to estimate viscosity changes due to hydrogenation. It was experimentally validated using three different oils, and the results show an overall relative average deviation of 3.7\%. The model was implemented in a transient CFD simulation of a three-phase monolith catalytic reactor for edible oil hydrogenation. Hydrogenation in Taylor flow was described with the unit cell approach. The influence of viscosity changes on the reaction yield and selectivity were investigated in relation with the coupling between hydrodynamics, mass transfer, and reaction kinetics. This effect proved to be significant in the former case; the reactor length was increased by a factor 1.5 , yielding approximately $30 \%$ conversion.
\end{abstract}

(Carlson et al., 2012; Koh and Wilcove, 2008). Consequently, there has been renewed interest in edible oil treatment processes, including hydrogenation. Hydrogenation is used in the food industry to minimize oil rancidity, ease packaging, and give a more solid and spreadable texture to the processed foods. This implies conversion of polyunsaturated oils, and more precisely, the saturation of carbon-carbon double bonds with hydrogen in the presence of a catalyst, as shown in Eq. (1). As a side reaction, isomerization can occur; hence large trans fatty acids (TFA) production (15-30\% fatty acid content) is the main disadvantage of the process as 


\section{Nomenclature}

\begin{tabular}{ll}
\multicolumn{2}{l}{ Acronyms } \\
CFD & computational fluid dynamic \\
CSO & crude sunflower oil \\
IV & iodine value \\
MR & monolith reactor \\
MUFA & monounsaturated fatty acids \\
PUFA & polyunsaturated fatty acids \\
RRO & refined rapeseed oil \\
RSO & refined sunflower oil \\
SFA & saturated fatty acids \\
TAG & triacylglycerol \\
TFA & trans fatty acids \\
UC & unit cell
\end{tabular}

Symbols

$a_{G L} \quad$ bubble interfacial area, $\left(\mathrm{m}_{B}^{2} \mathrm{~m}_{\mathrm{UC}}^{-3}\right)$

$c_{i} \quad$ concentration of component $i,\left(\mathrm{~mol} \mathrm{~m}_{L}^{-3}\right)$

$c_{i, \text { overall }}$ volume averaged concentration of component $i$, as volume averaged concentration
defined in Eq. (41), $\left(\mathrm{mol} \mathrm{m}_{L}^{-3}\right)$

$c_{H_{2}}^{*} \quad$ dissolved hydrogen concentration at saturation,

$\quad\left(\mathrm{mol} \mathrm{m}_{L}^{-3}\right)$

$d_{c} \quad$ channel diameter, $(\mathrm{m})$

$d S_{B} \quad$ elementary bubble surface, $\left(\mathrm{m}_{\mathrm{B}}^{2}\right)$

$d S_{W} \quad$ elementary wall surface, $\left(\mathrm{m}_{\mathrm{W}}^{2}\right)$

$D_{\text {TAG-oil }}$ triacylglycerol diffusivity in oil, $\left(\mathrm{m}^{2} \mathrm{~s}^{-1}\right)$

$D_{\mathrm{H}_{2} \text {-oil }}$ hydrogen diffusivity in oil, $\left(\mathrm{m}^{2} \mathrm{~s}^{-1}\right)$

$d V \quad$ elementary volume, $\left(\mathrm{m}^{3}\right)$

g gravity vector, $\left(\mathrm{m} \mathrm{s}^{-2}\right)$

$k_{1} \quad$ kinetic constant of MUFA hydrogenation rate, $\left(\mathrm{mol} \mathrm{kg}-1 \mathrm{Pd}^{-1}\right)$

$k_{2} \quad$ kinetic constant of PUFA hydrogenation rate, $\left(\mathrm{mol} \mathrm{kg}-1 \mathrm{sd}^{-1}\right)$

$K_{H} \quad$ hydrogen adsorption constant, $\left(\mathrm{m}^{3} \mathrm{~mol}^{-1}\right)$

$k_{G L} \quad$ gas-liquid mass transfer coefficient, $\left(\mathrm{m} \mathrm{s}^{-1}\right)$

$k_{G L} a_{G L} \quad$ volumetric gas-liquid mass transfer coefficient, $\left(\mathrm{s}^{-1}\right)$

$k_{L S} a_{L S} \quad$ volumetric liquid-solid mass transfer coefficient, $\left(\mathrm{s}^{-1}\right)$

$K_{M} \quad$ MUFA adsorption constant, $\left(\mathrm{m}^{3} \mathrm{~mol}^{-1}\right)$

$K_{S} \quad$ SFA adsorption constant, $\left(\mathrm{m}^{3} \mathrm{~mol}^{-1}\right)$

$L_{f} \quad$ lubrification film length, (m)

$L_{U C} \quad$ unit cell length, $(\mathrm{m})$

$M_{\text {oil }} \quad$ oil molar mass, $\left(\mathrm{g} \mathrm{mol}^{-1}\right)$

$M_{\text {TAG }}$ equivalent TAG molar mass, as defined in Eq. (8), $\left(\mathrm{g} \mathrm{mol}^{-1}\right)$

$n_{1} \quad$ power exponent for the viscosity as defined in Eq. (26), $(-)$

$n_{2} \quad$ power exponent for the viscosity as defined in Eq. (27), $(-)$

$N_{C, T A G}$ number of carbon atoms in equivalent triacylglycerol, $(-)$

$p \quad$ average number of $-\mathrm{CH}_{2}-$ groups per fatty acid in a given oil, (-)

$p^{\prime} \quad$ average number of insaturations per fatty acid in a given oil, (-)

$p_{\mathrm{H}_{2}} \quad$ hydrogen pressure, (atm)

$R \quad$ gas constant, $\left(\mathrm{J} \mathrm{mol}^{-1} \mathrm{~K}^{-1}\right)$

$R_{B} \quad$ bubble radius, (m)

$r_{i} \quad$ hydrogenation rate as defined through Eq. (30) to Eq. (35), $\left(\mathrm{mol} \mathrm{kg}_{\mathrm{Pd}}^{-1} \mathrm{~s}^{-1}\right)$

$T$ temperature, (K) u velocity vector, $\left(\mathrm{m} \mathrm{s}^{-1}\right)$

$U_{B} \quad$ bubble velocity, $\left(\mathrm{m} \mathrm{s}^{-1}\right)$

$u_{G S} \quad$ gas superficial velocity, $\left(\mathrm{m} \mathrm{s}^{-1}\right)$

$u_{L S} \quad$ liquid superficial velocity, $\left(\mathrm{m} \mathrm{s}^{-1}\right)$

$U_{T P} \quad$ two phase velocity, $U_{T P}=u_{G S}+u_{L S},\left(\mathrm{~m} \mathrm{~s}^{-1}\right)$

$V_{U C} \quad$ unit cell volume, $\left(\mathrm{m}_{\mathrm{UC}}^{3}\right)$

$w_{P d} \quad$ palladium mass fraction within the washcoat, (-)

$X \quad$ saturation degree, as defined in Eq. (12), (-)

$X_{f} \quad$ saturation degree at the channel outlet, (-)

$x_{C 18: 2} \quad$ PUFA molar fraction, (-)

$x_{C 18: 1} \quad$ MUFA molar fraction, (-)

$x_{C 18: 0} \quad$ SFA molar fraction, (-)

$z \quad$ axial position of the UC along the channel, ( $\mathrm{m}$ )

$z_{1} \quad$ axial position of the UC where MUFA concentration reaches its maximum at the wall, $(\mathrm{m})$

$z_{2} \quad$ axial position of the UC where MUFA concentration reaches zero at the wall, $(\mathrm{m})$

$z_{f} \quad$ channel length required to reach $X_{f},(\mathrm{~m})$

Greek Symbols

$\delta_{c} \quad$ washcoat thickness, (m)

$\delta_{f} \quad$ lubrification film thickness, (m)

$\Delta P \quad$ pressure drop, $(\mathrm{Pa})$

$\epsilon_{G} \quad$ gas hold-up, (-)

$\Lambda \quad$ optimized $A, B, C$ or $D$ coefficient given by Ceriani et al. (2007), (-)

$\mu_{L} \quad$ liquid dynamic viscosity, (Pa s)

$\phi_{W, i} \quad$ local molar flux at the channel wall for a given component $i$, $\left(\mathrm{mol} \mathrm{m}^{-2} \mathrm{~s}^{-1}\right)$

$\Phi_{W, F A_{i}} \quad$ overall molar flux at the channel wall for a given fatty acid $i,\left(\mathrm{~mol} \mathrm{~s}^{-1}\right)$

$\Phi_{B, H_{2}} \quad$ overall molar flux at the gas-liquid interface for $\mathrm{H}_{2}$, $\left(\mathrm{mol} \mathrm{s}^{-1}\right)$

$\rho_{L} \quad$ liquid density, $\left(\mathrm{kg} \mathrm{m}^{-3}\right)$

$\rho_{S} \quad$ washcoat density, $\left(\mathrm{kg} \mathrm{m}^{-3}\right)$

$\sigma_{L} \quad$ surface tension, $\left(\mathrm{N} \mathrm{m}^{-1}\right)$

$\Theta \quad$ solvent association parameter as defined in Eq. (26) (-)

$\theta_{D} \quad$ fractional surface coverage of PUFA on the catalyst surface, $(-)$

$\theta_{H} \quad$ fractional surface coverage of hydrogen on the catalyst surface, (-)

$\theta_{M} \quad$ fractional surface coverage of MUFA on the catalyst surface, (-)

\section{Dimensionless Groups}

$\mathrm{Ca} \quad$ Capillary number, $\frac{\mu_{L} U_{B}}{\sigma_{L}},(-)$

Re Reynolds number, $\frac{\rho_{L} U_{B} d_{c}}{\mu_{L}},(-)$

$\operatorname{Re}_{L} \quad$ liquid superficial Reynolds number, $\frac{\rho_{L} u_{L} d_{c}}{\mu_{L}},(-)$

$S_{L} \quad$ liquid Schmidt number for TAG, $\frac{\mu_{L} \mu_{L}}{\rho_{L} D_{\text {TAG-oil }}},(-)$

\section{Subscript}

0 at the channel inlet

ave average for the liquid in the unit cell

$B \quad$ bubble

$\max \quad$ local maximum value for the liquid in the unit cell

min local minimum value for the liquid in the unit cell

UC unit cell

W wall consumption of TFA has been shown to be harmful to human health (Mozaffarian et al., 2009). In addition, consumption of fully saturated fatty acids (SFA) should also be lowered to reduce the risk of cardiovascular diseases (Hooper et al., 2015). Current research is focusing on partial hydrogenation of polyunsaturated fatty acids (PUFA) while avoiding isomerization of the remaining cis carbon-carbon double bond (Belkacemi et al., 2006; Belkacemi et al., 2007). 


$$
-\mathrm{CH}=\mathrm{CH}-+\mathrm{H}_{2} \rightarrow-\mathrm{CH}_{2}-\mathrm{CH}_{2}-
$$

While the hydrogenation step is traditionally carried out in slurry-type reactors using Raney nickel, microstructured reactors (especially monolith reactors (MRs)) have received growing attention in recent years as alternative reactors for gas-liquid-solid catalytic reactions. Such reactors have well-known advantages, such as low pressure drop, plug flow behavior in channels, and higher gas-liquid mass transfer. Therefore, MRs might help to address conventional edible oil hydrogenation issues by reducing mass transfer limitations (thus enhancing selectivity), ensuring controlled hydrodynamics (in the so-called Taylor flow regime), and by preventing heavy metal poisoning through catalyst immobilization on the channel wall (in the form of a washcoat).

Computational fluid dynamic (CFD) simulations allow precise sizing of MRs (Durán Martínez et al., 2016; Durán Martínez, 2017; Shao et al., 2011); however, numerical results strongly depend on the physical properties of the oil (such as viscosity), which change as a function of oil saturation level. Consequently, the hydrodynamics, mass transfer, and reaction kinetics are strongly coupled. Therefore, the present work aims to quantify the effect of this coupling on MR hydrogenation using a predictive viscosity model in CFD simulations. We also propose a methodology for modeling of vegetable oil hydrogenation in monolith reactors.

\section{Processes for edible oil hydrogenation: current technologies and perspectives}

Crude edible oils undergo several processes before becoming refined oils. These steps might include dewaxing, degumming, bleaching, and deodorization. The main goal is to eliminate the following: (i) impurities such as water and free fatty acids, and (ii) micropollutants, such as tocopherols, sterols and sterol-esters, phospholipids, waxes, carotenoids, chlorophyll, and trace metals. The order and number of steps primarily depend on the type of oil. A hydrogenation step is often performed initially for deodorization (Gunstone, 2002). Slurry batch reactors are traditionally used for hydrogenation in the food industry. The reaction is carried out at pressures ranging from 2 to 6 bar and temperatures ranging from 150 to $180{ }^{\circ} \mathrm{C}$ (Wolff, 2003). Such high temperatures and low pressures favor production of monounsatured fatty acids (MUFA) and TFA. Catalysts such as Ni particles with an average size of $10 \mu \mathrm{m}$ are used, but they provide poor selectivity and cannot be used to prevent significant formation of TFA. Further, concerns have been raised regarding potential poisoning from nickel, which could leach out from the catalysts (Savchenko and Makaryan, 1999).

Metal selection might greatly impact on selectivity. While certain metals tend to favor TFA production, others promote the desired products, i.e. cis MUFA. Palladium appears as a good compromise catalyst as it provides selectivity of partial hydrogenation without isomerization (Ray and Carr, 1985; Belkacemi et al., 2006; Belkacemi et al., 2006). Belkacemi et al. (2007) also mentioned the use of a bimetallic catalyst and concluded that the addition of some specific metals ( $R u$ or Mo) can significantly reduce the cis/trans isomerization compared to the monometallic Pd catalyst, while others ( $\mathrm{Ni}, \mathrm{Sr}$ or $\mathrm{Co}$ ) have no beneficial effect. On the other hand, the presence of the second metal affects the content in saturated compounds to a lesser extent.

While batch-type reactors are common in the food industry because of their low operating costs and flexibility, continuoustype reactors have also been investigated, as they provide better contact area and contact time between oil and hydrogen (Veldsink et al., 1997). A tubular reactor fed with a preheated oil-catalyst slurry and hydrogen was studied by Snyder et al. (1978). Nielsen et al. (1960) and Schmidt (1970) investigated bubble column-type reactors, and Boyes et al. (1995) studied a concurrent downflow fixed bed contactor. Boger et al. (2004) used a batch reactor including a monolith stirrer coated with a Pd catalyst and compared its performance to that of a slurry type reactor. It can be concluded from these studies that contact between the gas and liquid phases is a key parameter for the design of effective hydrogenation reactors (Veldsink et al., 1997). This motivates interest in MRs. Such reactors are composed of numerous millimetric channels, which are coated with a thin catalytic layer (thickness: $10-50 \mu \mathrm{m}$ ) to ensure that internal transfer resistance is not limiting. A specific flow regime is sought in the channels, where gas bubbles are trapped between liquid slugs (so-called Taylor flow or slug flow). These flow conditions minimize pressure drop while providing higher gas-liquid mass transfer and plug flow behavior. Moreover, MRs can be built up with a high conductivity metal scaffold, and some of the channels can be dedicated to cooling in order to efficiently remove heat produced during the hydrogenation reaction. Numerous studies have focused on different aspects of MRs, where an air-water system was used in most prior studies (Mishima and Hibiki, 1996; Yang and Shieh, 2001). Furthermore, the fluid distribution at the monolith entrance, flow regimes within the channels, and gas-liquid mass transfer received focus in earlier studies.

\section{New group contribution-based model for viscosity prediction}

\subsection{Literature overview}

The rheological behavior of pure fatty compounds and fatty mixtures has been shown to be Newtonian (Timms, 1985), and equations describing their viscosity as a function of temperature (Noureddini et al., 1992; Fisher, 1998; Gupta et al., 2007; Coupland and McClements, 1997; Dutt and Prasad, 1989; Kim et al., 2010) and composition (Azian et al., 2001; Valeri and Meirelles, 1997; Eiteman and Goodrum, 1994; Rabelo et al., 2000; Fasina et al., 2006) have been proposed. Using a large database (763 experimental values), Ceriani et al. (2007) developed a group contribution model for predicting viscosity of pure fatty compounds, among which triaclyglycerols (TAG), which are the primary component in edible oil. Results from this model were satisfactory for pure fatty acids and pure TAGs with 5.7\% (Noureddini et al., 1992) and less than 5\% (Ceriani et al., 2007; Valeri and Meirelles, 1997; Rabelo et al., 2000; Joglekar and Watson, 2013) average deviation from the experimental data, respectively. Even though the model was only designed for pure fatty molecules, Ceriani et al. (2007) proposed a method for transposing its use to edible oils i.e. complex TAG mixtures. Nevertheless, the model is less accurate in this case, either when using a typical fatty acid composition (Noureddini et al., 1992; Miller et al., 1994; Silva and Singh, 1995; Thomas et al., 2000; Rabelo et al., 2000; Morrison and Robertson, 1978; Topallar et al., 1995) or more refined characterizations (Hasenhuettl, 2000; Haynes, 2014); viscosity values were predicted with a relative average deviation ranging from 3\% (Thomas et al., 2000) up to 32\% (Miller et al., 1994). This assessment raises the need for a more suitable model for describing the viscosity of an edible oil during hydrogenation.

\subsection{Reference model description}

Ceriani et al. (2007) developed a group contribution model for estimating the dynamic viscosity of pure fatty compounds, which is a function of the temperature and chemical structure of the considered molecule. The investigated molecule is divided into seven 
predefined functional groups. The contribution of each of these groups and the class (fatty acid, alcohol, acylglycerol, or ester) of the molecule determine the dynamic viscosity of the fatty compound, as defined in Eq. (2):

$$
\begin{aligned}
\ln \mu_{L}= & \sum_{k} N_{k}\left(A_{1 k}+\frac{B_{1 k}}{T}-C_{1 k} \ln T-D_{1 k} T\right) \\
& +M\left[\sum_{k} N_{k}\left(A_{2 k}+\frac{B_{2 k}}{T}-C_{2 k} \ln T-D_{2 k} T\right)\right]+Q
\end{aligned}
$$

where $\mu_{L}$ is the dynamic viscosity in mPa s of the considered molecule, $N_{k}$ is the number of groups indexed by $k, T$ is the temperature, $M$ is the molecular weight of the considered molecule, $Q$ is a correction term (see Eq. (3)), and $A_{1 k}, B_{1 k}, C_{1 k}, D_{1 k}, A_{2 k}, B_{2 k}, C_{2 k}$, and $D_{2 k}$ are regression parameters for group $k$.

$Q=\xi_{1} q+\xi_{2}$

$q$ is defined in Eq. (4). $\xi_{1}$ and $\xi_{2}$ are expressed in Eqs. (5) and (6), respectively, and are functions of the class of the compound.

$q=\alpha+\frac{\beta}{T}-\gamma \ln T-\delta T$

$\alpha, \beta, \gamma, \delta$ are optimized parameters.

$\xi_{1}=f_{0}+N_{C} f_{1}$

$\xi_{2}=s_{0}+N_{C S} s_{1}$

$f_{0}, f_{1}, s_{0}$, and $s_{1}$ are regression parameters that depend on the class of the compound. $N_{C}$ is the number of carbons in the molecule and $N_{C S}$ is the number of carbons in the alcoholic part of the ester class molecule.

Following their work, a TAG molecule with the general chemical formula presented in Fig. (1) is decomposed, as shown in Table 1.

Hence, only $-\mathrm{CH}_{2}$ - and $-\mathrm{CH}=$ groups differ from one TAG to another, depending on the three fatty acids of which they are composed. Assuming that the dynamic viscosity of the studied oil only depends on its functional group composition, an equivalent TAG made of a single fatty acid is deduced: the latter comprises one - $\mathrm{COO}$ - group, one $-\mathrm{CH}_{3}$ group, and the average numbers of $\mathrm{CH}_{2^{-}}$groups $(p)$ and insaturations $\left(p^{\prime}\right)$ in the TAG, where one insaturation counts as two $-\mathrm{CH}=$ groups. Note that $p$ and $p^{\prime}$ are not necessarily integers and that no distinction is made between cis and trans double bonds. This equivalent TAG is shown in Fig. 2.

This leads to the new decomposition shown in Table 2, which is used directly in Ceriani's model to predict viscosity at a given temperature.

\subsection{Revisited model}

The present work shifts from Ceriani's fully predictive model to a semi-predictive model for edible oils undergoing hydrogenation. This new model is based on reference data for viscosity values of the oil of interest at a given saturation degree for different temperatures. Ceriani's model prediction capabilities are then exploited to infer other viscosity values when changing oil saturation degree.

During hydrogenation, the number of carbons $\left(N_{C, T A G}\right)$, defined in Eq. (7), remains invariant in the equivalent TAG molecule while $-\mathrm{CH}=$ groups turn into $-\mathrm{CH}_{2}-$ groups. For a given fatty acid compo-
Table 1

Triacylglycerol decomposition (Ceriani et al., 2007).

\begin{tabular}{cc}
\hline Group & Number \\
\hline$-\mathrm{CH}_{2}-\mathrm{CH}-\mathrm{CH}_{2-}$ & 1 \\
$-\mathrm{COO}-$ & 3 \\
$-\mathrm{CH}_{2-}$ & $l+m+n$ \\
$-\mathrm{CH}=$ & $2\left(l^{\prime}+m^{\prime}+n^{\prime}\right)$ \\
$-\mathrm{CH}_{3}$ & 3 \\
\hline
\end{tabular}

sition in the considered oil before hydrogenation, $N_{C, T A G}$ is known and Eq. (2) is then only a function of $p^{\prime}$ and temperature.

$N_{C, T A G}=9+3 p+6 p^{\prime}$

The molecular weight of the equivalent TAG molecule $\left(M_{\text {TAG }}\right)$ is then defined in Eq. (8):

$M_{\text {TAG }}=N_{C, T A G} M_{C}+6 M_{O}+\left[14+6\left(p+p^{\prime}\right)\right] M_{H}$

where $M_{C}, M_{O}$, and $M_{H}$ are respectively the atomic mass of carbon, oxygen, and hydrogen.

Therefore, Eq. (2) can be re-written as shown in Eq. (9):

$\ln \mu_{L}=K_{0}+K_{1} p^{\prime}+K_{2} p^{\prime 2}$

where $K_{i}=A_{i}+B_{i} / T-C_{i} \ln T-D_{i} T$ for $i=[0 ; 1 ; 2]$. Parameters $A_{1}$ to $D_{1}$, and $A_{2}$ to $D_{2}$, are obtained from Eq. (2) and are functions of the parameters given by Ceriani et al. (2007) for each functional group, $N_{C, T A G}, M_{C}, M_{O}$, and $M_{H}$. Their expressions are available in Eqs. (10) and (11), where $\Lambda$ stands for $A, B, C$, or $D$.

$$
\begin{aligned}
\Lambda_{1} & =6\left[-\Lambda_{1, C H_{2}}+\Lambda_{1, C H}\right. \\
& -M_{H}\left(3 \Lambda_{2, C H_{3}}+\left(N_{C, T A G}-9\right) \Lambda_{2, C H_{2}}+3 \Lambda_{2, C O O}+\Lambda_{2, C H_{2}-C H-C H_{2}}\right) \\
& \left.+\left(N_{C, T A G} M_{C}+6 M_{O}+\left(14+2 N_{C, T A G}-18\right) M_{H}\right)\left(-\Lambda_{2, C H}+\Lambda_{2, C H}\right)\right]
\end{aligned}
$$

$\Lambda_{2}=36 M_{H}\left(\Lambda_{2, \mathrm{CH}_{2}}-\Lambda_{2, \mathrm{CH}}\right)$

Parameters $A_{0}$ to $D_{0}$ in Eq. (9) are to be optimized using experimental viscosity measurements at different temperatures when $p^{\prime}$ is equal to zero, meaning when the oil is completely hydrogenated. Accordingly, the model uses the saturated oil viscosity as a reference; therefore, viscosity at any other advancement can be computed using the other eight parameters. This approach allows calibration of the model and extends the application of the model in Ceriani et al. (2007) to edible oils, which are complex TAG mixtures containing impurities (up to $4 \%$ by weight). Because it is easier to measure the viscosity for the raw oil rather than the fully hydrogenated oil, the hydrogenation level (or saturation degree) $X$ is included in Eq. (12):

$X=\frac{p_{0}^{\prime}-p^{\prime}}{p_{0}^{\prime}}$

where $p_{0}^{\prime}$ is the value of $p^{\prime}$ for the oil before hydrogenation. Eq. (9) then becomes Eq. (13).

$\ln \mu_{L}=K_{0}^{\prime}+K_{1}^{\prime} X+K_{2}^{\prime} X^{2}$

where $K_{i}^{\prime}=A_{i}^{\prime}+B_{i}^{\prime} / T-C_{i}^{\prime} \ln T-D_{i}^{\prime} T$ for $i=[0 ; 1 ; 2]$. Parameters $A_{1}^{\prime}$ to $D_{2}^{\prime}$ are functions of the previously calculated parameters $A_{1}$ to $D_{2}$

$$
\begin{array}{lr}
\mathrm{CH}_{2}-\mathrm{COO}-\mathrm{R}_{1 l^{\prime}} & \mathrm{CH}_{2}-\mathrm{COO}-\left(\mathrm{CH}_{2}\right)_{1}-(\mathrm{HC}=\mathrm{CH})_{\mathrm{l}^{-}}-\mathrm{CH}_{3} \\
\mathrm{CH}-\mathrm{COO}-\mathrm{R}_{\mathrm{mm}} & \mathrm{CH}-\mathrm{COO}-\left(\mathrm{CH}_{2}\right)_{\mathrm{m}}-(\mathrm{HC}=\mathrm{CH})_{\mathrm{m}^{\prime}}-\mathrm{CH}_{3} \\
\mathrm{CH}_{2}-\mathrm{COO}-\mathrm{R}_{\mathrm{nn}^{\prime}} & \mathrm{CH}_{2}-\mathrm{COO}-\left(\mathrm{CH}_{2}\right)_{\mathrm{n}}-(\mathrm{HC}=\mathrm{CH})_{\mathrm{n}^{\prime}}-\mathrm{CH}_{3}
\end{array}
$$

Fig. 1. Triacylglycerol chemical formula (Ceriani et al., 2007). 


\section{$\mathrm{CH}_{2}-\mathrm{COO}-\left(\mathrm{CH}_{2}\right)_{\mathrm{p}}-(\mathrm{HC}=\mathrm{CH})_{\mathrm{p}^{\prime}}-\mathrm{CH}_{3}$ \\ $\mathrm{CH}-\mathrm{COO}-\left(\mathrm{CH}_{2}\right)_{\mathrm{p}}-(\mathrm{HC}=\mathrm{CH})_{\mathrm{p}^{\prime}}-\mathrm{CH}_{3}$ \\ $\mathrm{CH}_{2}-\mathrm{COO}-\left(\mathrm{CH}_{2}\right)_{\mathrm{p}}-(\mathrm{HC}=\mathrm{CH})_{\mathrm{p}^{\prime}}-\mathrm{CH}_{3}$}

Fig. 2. Equivalent triacylglycerol chemical formula (Ceriani et al., 2007).

Table 2

Equivalent triacylglycerol decomposition (Ceriani et al., 2007).

\begin{tabular}{cc}
\hline Group & Number \\
\hline$-\mathrm{CH}_{2}-\mathrm{CH}-\mathrm{CH}_{2}-$ & 1 \\
$-\mathrm{COO}-$ & 3 \\
$-\mathrm{CH}_{2}-$ & $3 p$ \\
$-\mathrm{CH}=$ & $6 p^{\prime}$ \\
$-\mathrm{CH}_{3}$ & 3 \\
\hline
\end{tabular}

and are defined in Eqs. (14) and (15). $A_{0}^{\prime}$ to $D_{0}^{\prime}$ are optimized using viscosity measurements for the studied oil in its original state (before hydrogenation).

$\Lambda_{1}^{\prime}=-p_{0}^{\prime}\left(\Lambda_{1}+2 p_{0}^{\prime} \Lambda_{2}\right)$

$\Lambda_{2}^{\prime}=p_{0}^{\prime 2} \Lambda_{2}$

\subsection{Experimental set-ups and procedures}

Three different vegetable oils were studied: a refined sunflower oil (RSO), a crude sunflower oil (CSO), and a refined rapeseed oil (RRO). The two refined oils were bought in a supermarket (Carrefour group), and the crude oil was supplied by Huiles Bertin (Le Plessis Belleville, France).

Hydrogenation tests were carried out in 100 and $200 \mathrm{~mL}$ autoclave reactors operating at predefined pressures (ranging from 10 to $20 \mathrm{barg}$ ) and temperatures (ranging from 100 to $160{ }^{\circ} \mathrm{C}$ ) with $1 \% \mathrm{Pd} / \mathrm{Al}_{2} \mathrm{O}_{3}$ beads (Alfa Aesar) as a catalyst.

The fatty acid content in the raw oils was analyzed using gas chromatography. Samples were methylated with boron trifluoride and introduced in an FAME column $(0.25 \mathrm{~mm}$ ID $\times 50 \mathrm{~m}$, Agilent Select). The oven temperature was set to $165{ }^{\circ} \mathrm{C}$ for $25 \mathrm{~min}$, then to $200{ }^{\circ} \mathrm{C}$ for $13.5 \mathrm{~min}$, and finally to $250{ }^{\circ} \mathrm{C}$ for $5 \mathrm{~min}$. The carrier gas pressure was maintained at $220 \mathrm{kPa}$ with a split flow of $60 \mathrm{~mL} /$ min.

Iodine values in the oils were also determined using the standardized ISO 3961 Wijs method.

The dynamic viscosity of the oils was measured from 20 to $100{ }^{\circ} \mathrm{C}$ using a rheometer with a $60 \mathrm{~mm} 2{ }^{\circ} \mathrm{Cone}$-plane geometry (Thermo Scientific HAAKE MARS 40) at shear rate ranging from 1 to $500 \mathrm{~s}^{-1}$. The rheometer accuracy in these conditions was verified against high temperature viscosity standards (Paragon Scientific Ltd.), revealing an average relative deviation of $1.6 \%$. As a complement, cross verification of kinematic viscosity values was performed with refined sunflower oil (before hydrogenation) using a capillary Ubbelohde type viscometer (Schott AVS 440).

\subsection{Data available in the literature}

To the authors' knowledge, the viscosity of hydrogenated edible oils has been barely studied. Topallar et al. (1995) measured the dynamic viscosity of sunflower oil at different temperatures and determined its fatty acid content before and after partial hydrogenation. However, their values seem surprisingly low compared to standard viscosity values of sunflower oil (Hasenhuettl, 2000), and these data were not retained for model optimization or validation. Morrison and Robertson (1978) studied two different types of sunflower oils, one with a high linoleic profile and the other one a high oleic profile. Both oils underwent hydrogenation, and compositions were measured before and after reaction. The viscosity was also measured, but only at $70{ }^{\circ} \mathrm{C}$.

\subsection{Experimental data}

The composition of unhydrogenated refined sunflower oil, crude sunflower oil, and refined rapeseed oil before are given in Table 3.

Their viscosities were measured at different temperatures, and the values are given in Table 4.

Five different hydrogenation tests were conducted with the refined sunflower oil, three for the refined rapeseed oil, and two for the crude sunflower oil. Thereafter, the liquid phase was collected and analyzed as previously described.

\subsection{Model assessment}

Variables $p_{0}, p_{0}^{\prime}$, and $N_{C, T A G}$ were calculated from the oil composition in fatty acids, which are shown in Table 3 for the experimentally investigated samples. Values of these variables are available in Table 5.

Table 3

Fatty acid content in unhydrogenated vegetable oils (wt\%).

\begin{tabular}{cccc}
\hline Fatty Acid & RSO & CSO & RRO \\
\hline C14:0 & 0.08 & 0.10 & 0.05 \\
C16:0 & 6.59 & 6.90 & 4.71 \\
C16:1 & 0.14 & 0.17 & 0.27 \\
C17:1 & - & - & 0.07 \\
C18:0 & 3.24 & 2.97 & 1.58 \\
C18:1 & 29.74 & 29.03 & 62.62 \\
C18:2 & 58.75 & 59.31 & 19.88 \\
C18:3 & 0.06 & 0.53 & 8.25 \\
C20:0 & 0.24 & 0.23 & 0.55 \\
C20:1 & 0.16 & - & 1.29 \\
C22:0 & 0.70 & 0.46 & 0.31 \\
C22:1 & - & 0.06 & 0.09 \\
C24:0 & 0.26 & 0.23 & 0.13 \\
C24:1 & - & - & 0.15 \\
& & &
\end{tabular}


Table 4

Viscosities values for unhydrogenated oils (mPa s).

\begin{tabular}{cccc}
\hline Temperature $\left({ }^{\circ} \mathrm{C}\right)$ & $\mathrm{RSO}^{\mathrm{a}}$ & $\mathrm{CSO}^{\mathrm{b}}$ & $\mathrm{RRO}^{\mathrm{b}}$ \\
\hline 20 & 64.00 & 61.0 & 67.9 \\
40 & 29.38 & 28.4 & 30.8 \\
60 & 16.06 & 15.8 & 16.2 \\
80 & 9.95 & 9.9 & 10.2 \\
100 & - & 6.9 & 6.8
\end{tabular}

a Measured using a viscometer (see Section 3.4).

b Measured using a rheometer (see Section 3.4).

$p^{\prime}$ value and the saturation degree $X$ for each hydrogenated sample was determined from its respective iodine value (IV) (see Eq. (16)). The $X$ values are listed in Table 6 .

$I V=100 \frac{3 p^{\prime} M_{I_{2}}}{M_{T A G}}$

where $M_{I_{2}}$ is the molecular weight of iodine.

Parameters $A_{0}^{\prime}$ through $D_{0}^{\prime}$ for the experimentally investigated oils (see Table 7) were calculated using linear regression with MATLAB 2016b; these data are listed in Table 4.

The experimental viscosity data for the unhydrogenated RSO is compared with the values from the present model and the prediction from Ceriani et al. in Fig. 3. Because $A_{0}^{\prime}$ to $D_{0}^{\prime}$ parameters were regressed from these very data points; the present model (PM) perfectly fits the experimental trend, whereas the model of Ceriani et al. (CM), which was only based on the equivalent TAG functional groups, shows a $14 \%$ average relative deviation.

The same data and those obtained after hydrogenation tests (RSO\#1 and RRO\#1) are shown respectively in Figs. 4 and 5 along with the predictions from different models. The viscosity of RSO\#1 oil is approximately $20 \%$ larger than that of RSO. In addition, the average standard deviation with respect to the experimental viscosity data are $18.2 \%$ for the model from Ceriani et al. and only $4.0 \%$ for the present model. Note that the viscosity values predicted with both models for the hydrogenated oil are not plotted at low temperatures for which partially saturated fat might be solid.

Table 8 shows the average relative deviations between the experimental viscosity values (measured after each hydrogenation from 60 to $100^{\circ} \mathrm{C}$ ) and the values predicted with the two models.

It follows that the mean average relative deviation is $3.7 \%$ for the proposed model against $16.9 \%$ for Ceriani's model.

The same approach was applied to the data of Morrison and Robertson (1978), corresponding to high linoleic (HL) and high oleic (HO) profile oils undergoing hydrogenation. Thanks to raw and hydrogenated oil composition given in their study, the $p^{\prime}$ values and saturation degrees $X$ were determined to be $10.4 \%$ and $3.1 \%$ for $\mathrm{HL}$ and $\mathrm{HO}$, respectively. In this case, the present model could be used to predict their viscosity data with relative deviations of $2.8 \%$ and $2.2 \%$ compared to $27 \%$ and $24 \%$ using Ceriani's model, respectively.

The present model can be used to predict the viscosity of a given edible oil undergoing hydrogenation satisfactorily. Hence, it can be implemented, for instance, in CFD code to account for the evolution of transport properties during the reaction. This is done in the next section, where it appears in the momentum

Table 5

Calculated values of $p, p^{\prime}$, and $N_{C, T A G}$.

\begin{tabular}{cccc}
\hline Variables & RSO & CSO & RRO \\
\hline$p_{0}$ & 12.94 & 12.90 & 13.37 \\
$p_{0}^{\prime}$ & 1.477 & 1.484 & 1.290 \\
$N_{C, \text { TAG }}$ & 56.68 & 56.61 & 56.84 \\
\hline
\end{tabular}

Table 6

Calculated saturation degree $X$ (uncertainty based on iodine values repeatability).

\begin{tabular}{cccc}
\hline Hydrogenation number & RSO & CSO & RRO \\
\hline$\# 1$ & $26.5 \% \pm 1.6 \%$ & $13.3 \% \pm 1.5 \%$ & $34.1 \% \pm 1.1 \%$ \\
$\# 2$ & $22.0 \% \pm 1.5 \%$ & $16.8 \% \pm 2.3 \%$ & $21.8 \% \pm 3.4 \%$ \\
$\# 3$ & $37.4 \% \pm 4.0 \%$ & - & $24.6 \% \pm 4.2 \%$ \\
$\# 4$ & $25.2 \% \pm 1.2 \%$ & - & - \\
$\# 5$ & $66.7 \% \pm 0.6 \%$ & - & - \\
\hline
\end{tabular}

Table 7

Model parameters for the reference oils optimized from viscosity measurements (before hydrogenation).

\begin{tabular}{cccc}
\hline Coefficient & RSO & CSO & RRO \\
\hline$A_{0}^{\prime}$ & -548.78 & -293.84 & -372.07 \\
$B_{0}^{\prime}$ & 20,824 & 13,675 & 16,129 \\
$C_{0}^{\prime}$ & -90.555 & -46.420 & -59.726 \\
$D_{0}^{\prime}$ & 0.11091 & 0.0423 & 0.0614 \\
\hline
\end{tabular}

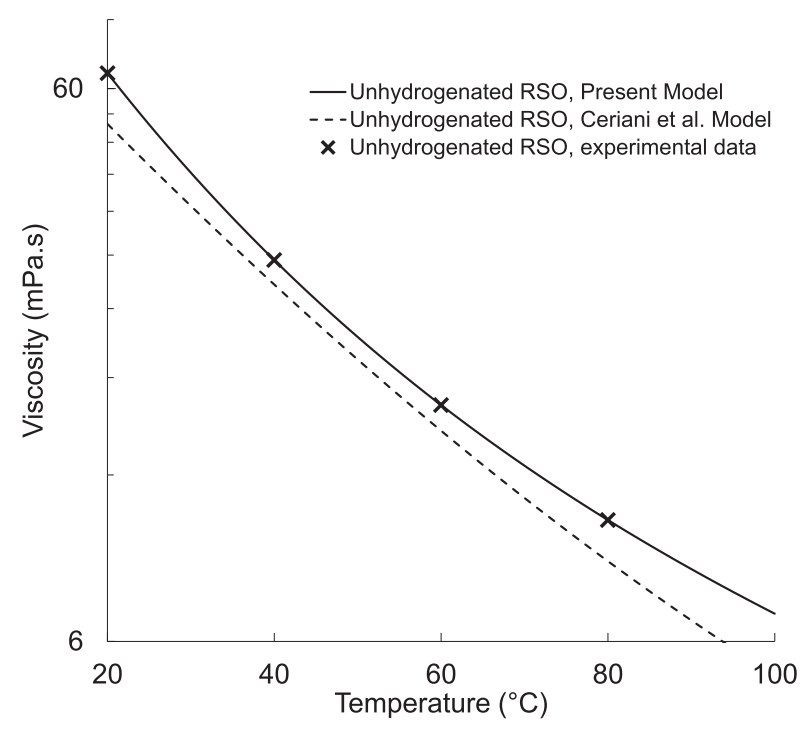

Fig. 3. Experimental data and predicted viscosity values for unhydrogenated RSO.

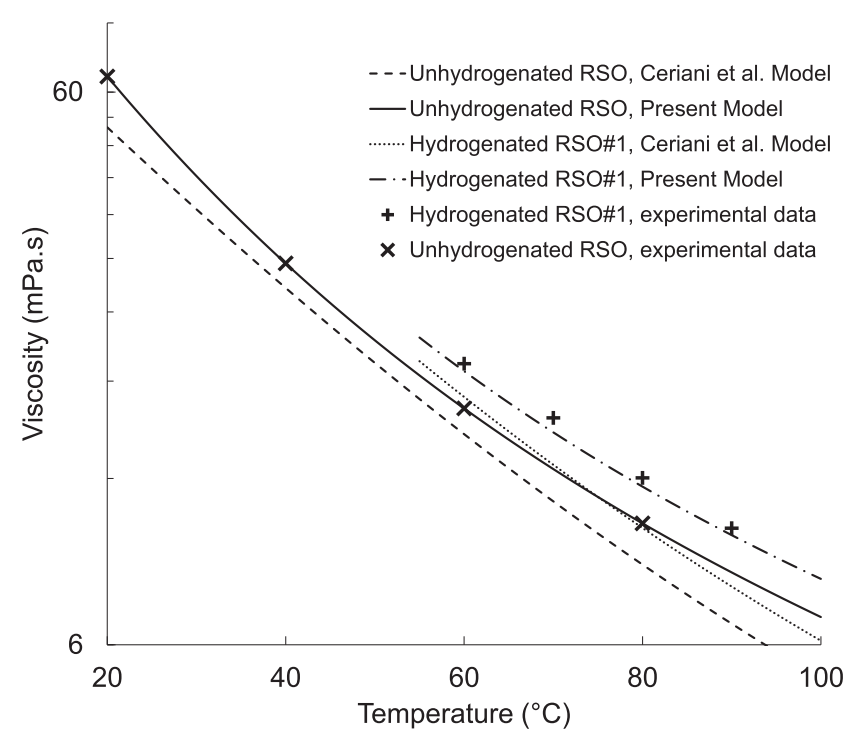

Fig. 4. Viscosity data for unhydrogenated RSO and RSO\#1: comparison of experimental measurements and predictions from the two models. 


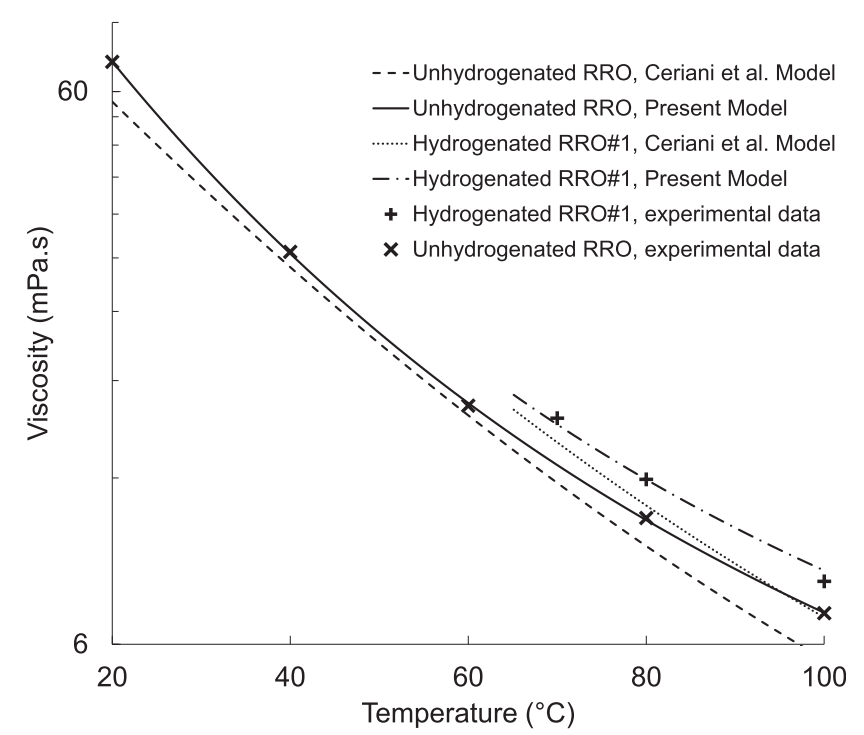

Fig. 5. Viscosity data for unhydrogenated RRO and RRO\#1: comparison of experimental measurements and predictions from the two models.

balance and diffusivity expression. This semi-predictive approach can be applied to other group contribution models, such as those developed by Ceriani and Meirelles (2004) for vapor pressure and heat capacity of fatty compounds, and to the surface tension model developed by Díaz-Tovar et al. (2011).

\section{Viscosity prediction model applied to CFD simulation of oil hydrogenation in a monolith reactor}

\subsection{Strategy}

The development of a pre-design tool for predicting conversion and selectivity results of monolith heat exchanger-reactors for hydrogenation of edible (sunflower) oil is examined in this section. These reactors include 1 to $4 \mathrm{~mm}$ diameter channels pierced in a heat conductive metal scaffold, such as aluminum. It should be recalled that some channels are dedicated to cooling the reactor with a circulating thermal fluid, while others are dedicated to the catalytic reactions by holding a few micron thin catalytic layer on their walls. The latter channels are fed by gas-liquid distributors, such as spray nozzles, shower heads, or more sophisticated devices, to get closer to a uniform phase distribution in the channels. As stated in Section 1, the reactive channels host a series of bubbles and liquid slugs in the desired conditions, the so-called Taylor flow or plug flow, which is known to enhance gas-liquid mass transfer. The full problem is three-dimensional and is strongly interwoven with coupled multiphysics phenomena (hydrodynamics, mass and heat transfer, and a catalytic reaction). Moreover, due to these complex relationships, the problem must be described at the catalytic layer, bubble, channel, and reactor scales. In the case of edible oils, multiphysics coupling is reinforced, because the physical properties (viscosity and surface tension to a lesser extent) depend upon oil saturation level, as seen previously. COMSOL MULTIPHYSICS ${ }^{\circledR}$ software was selected for these simulations as it allows a description of each phenomenon at the right level of complexity. Although the hydrogenation reaction is highly exothermic, the temperature in the reactive channels is assumed to be uniform, assuming that the flowrate of the thermal oil is large enough in the neighboring cooling channels and that the wall of the monolith has high thermal conductivity (Durán Martínez, 2017). The effect of an uneven gas and liquid distribution can be then easily accounted for by combining the channel outflows fed with different gas and liquid flow rates. These two assumptions facilitate a single channel approach.

\subsubsection{General approach}

The unit cell (UC) approach, which was inspired by prior studies Fukagata et al. (2007) and Gupta et al. (2010), can be used to describe Taylor flow in a cylindrical and vertical milli-channel while neglecting end effects at the inlet and outlet of the capillary. This represents the elementary pattern of the flow: a single bubble surrounded by two liquid slug halves is considered in a reference frame moving with the bubble. In this reference frame, the numerical problem is non-stationary. Superficial gas and liquid velocities, $u_{G S}$ and $u_{L S}$, have been adjusted to ensure the system is in the Taylor flow regime. Note that there is no flow pattern map available for hydrogen and edible oil. Therefore, the inlet superficial gas and liquid velocities $u_{G S, 0}$ and $u_{L S, 0}$ were defined using the hydrogen-water flow diagram given by Haase et al. (2016). Bubble deformation in a fully developed Taylor flow in mini- and microchannels was discussed extensively in previous CFD studies (Fukagata et al. (2007) and Gupta et al. (2009, 2010)). In this study, the bubble is considered to have a constant and idealized shape, which is relevant provided the capillary number $\mathrm{Ca}$ is sufficiently low $\left(\mathrm{O}\left(10^{-3}\right)\right)$ (Bretherton, 1961, Haase et al., 2016). Ca is defined in Eq. (17), where $\sigma_{L}$ is the surface tension and $U_{B}$ is the bubble velocity.

$\mathrm{Ca}=\mu_{L} U_{B} / \sigma_{L}$

It has been verified that in these velocity conditions, the deduced $\mathrm{Ca}$ numbers remain at the desired order of magnitude $\left(\mathrm{O}\left(10^{-3}\right)\right)$. The bubble can subsequently be described as a cylindrical body with hemispheres at both ends (Durán Martínez et al., 2016). A 2D-axisymmetric domain is used to represent the cylindrical channel with circular cross-section. Two-phase flow velocity $U_{T P}$ (defined in Eq. (18)), bubble velocity $U_{B}$, and $C a$ are related through Eq. (19) from Bretherton (1961). Furthermore, Eq. (20) defines the relation between the gas hold-up $\epsilon_{G}$ in the UC, $u_{G S}$ and $U_{B}$.

$U_{T P}=u_{L S}+u_{G S}$

Table 8

Average relative deviations between experimental viscosity data and the values predicted with the two models.

\begin{tabular}{|c|c|c|c|c|c|c|}
\hline \multirow{2}{*}{$\begin{array}{l}\text { Hydrogenation } \\
\text { number }\end{array}$} & \multicolumn{2}{|c|}{ RSO } & \multicolumn{2}{|c|}{ CSO } & \multicolumn{2}{|c|}{ RRO } \\
\hline & $\mathrm{PM}^{\mathrm{a}}$ & $\mathrm{CM}^{\mathrm{b}}$ & $\mathrm{PM}^{\mathrm{a}}$ & $\mathrm{CM}^{\mathrm{b}}$ & $\mathrm{PM}^{\mathrm{a}}$ & $\mathrm{CM}^{\mathrm{b}}$ \\
\hline \#1 & $4.0 \%$ & $18.2 \%$ & $3.4 \%$ & $19.6 \%$ & $2.4 \%$ & $11.3 \%$ \\
\hline \#2 & $1.1 \%$ & $15.1 \%$ & $2.9 \%$ & $18.3 \%$ & $10.0 \%$ & $19.1 \%$ \\
\hline \#3 & $1.9 \%$ & $16.2 \%$ & - & - & $3.2 \%$ & $14.7 \%$ \\
\hline$\# 4$ & $2.8 \%$ & $18.1 \%$ & - & - & - & - \\
\hline \#5 & $7.1 \%$ & $11.6 \%$ & - & - & - & - \\
\hline
\end{tabular}

\footnotetext{
a Present Model
}

b Ceriani et al. Model. 
$\frac{U_{B}-U_{T P}}{U_{B}}=1.29(3 \mathrm{Ca})^{2 / 3}$

$u_{G S}=\epsilon_{G} U_{B}$

The liquid film thickness is deduced from the relationship developed by Aussillous and Quéré (2000):

$\frac{\delta_{f}}{d_{c}}=\frac{0.66 C a^{2 / 3}}{1+3.33 C a^{2 / 3}}$

Viscosity differences between gas and liquid result in a much greater pressure gradient in the liquid than in the bubble. Moreover, shear stress can be neglected at the bubble surface (slip boundary condition). At the considered temperatures, oil vaporization is also negligible, and the bubble can be considered to be made of hydrogen only. Consequently, the only equations to be solved are those describing the liquid phase. Such an approach has been validated by Durán Martínez et al. (2016).

In order to quantify the impact of changes in the oil physical properties on conversion and selectivity of the hydrogenation reactor, two different cases based on otherwise identical conditions were investigated. The first case assumes that these properties remain constant (Case 1A), while the second case accounts for their evolution with saturation degree (Case 2A). These calculations were applied to the previously studied refined sunflower oil (RSO) with polyunsaturated (C18:2), monounsaturated (C18:1), and saturated (C18:0) fatty acids. Thus, cis/trans isomerization reactions are not accounted for here, as shown by the overall reaction scheme given in Eq. (22). In addition, hydrogenation reactions only take place at the channel wall, on which the catalytic washcoat is anchored. The inlet composition, physical properties, and operating conditions are listed in Table 9.

$\mathrm{C} 18: 2 \underset{(2)}{\stackrel{+\mathrm{H}_{2}}{2}} \mathrm{C} 18: 1 \underset{(1)}{\stackrel{+\mathrm{H}_{2}}{\longrightarrow}} \mathrm{C} 18: 0$

As previously discussed, the temperature is assumed constant along the reactor, and variations in the hydrogen pressure were neglected. Changes in density and surface tension due to the reaction were ignored (Topallar et al., 1995), while, in Case 2A, viscosity was calculated analytically as a function of the local saturation level using the developed model with the RSO coefficients available in Table 7.

Calculations were conducted for the liquid phase only, and the bubble and UC volumes were assumed constant (Durán Martínez et al., 2016; van Baten and Krishna, 2004). While the geometry and thus the gas-liquid interfacial area remain unchanged during the time-dependent calculations, the theoretical reduction in the bubble volume (since hydrogen is consumed) is considered here by updating the velocity at the wall $U_{B}$. Mass flux leaving the bubble is integrated with respect to time and $\epsilon_{G}$ is implicitly updated. $U_{B}$ is then deduced from Eqs. (19) and (20). Note in that in Case 2A, viscosity changes were considered when evaluating $U_{B}$. Calculations were stopped when the implicit variable $\epsilon_{G}$ reached the minimum gas hold-up for Taylor flow conditions $\epsilon_{G, \text { minin }}$, i.e., when the bubble would theoretically be a sphere. This corresponded to a saturation degree $X$ approximately equal to $32 \%$.
Finally, the axial position of UC in the considered channel was known when integrating $U_{T P}$ with respect to time.

\subsubsection{Mathematical modeling}

In both cases, the liquid flow is incompressible, laminar $(R e<840)$, and upward. Hydrodynamic equations were solved using COMSOL MULTIPHYSICS ${ }^{\circledR} 5.4$ :

Continuity equation:

$\nabla \cdot\left(\rho_{L} \mathbf{u}\right)=0$

Momentum equation:

$\frac{\partial \rho_{L} \mathbf{u}}{\partial t}+\rho_{L}(\mathbf{u} \cdot \nabla) \mathbf{u}=-\nabla P+\nabla \cdot\left[\mu_{L}\left(\nabla \mathbf{u}+\nabla \mathbf{u}^{\mathbf{T}}\right)\right]+\rho_{L} \mathbf{g}$

In Case $2 \mathrm{~A}$, the liquid viscosity $\mu_{L}$ is given in the previously discussed model and varies locally due to the concentration gradient. Mass transport in the liquid phase accounts for the different chemical species of interest $i$ (see Eq. (25)): hydrogen $\left(\mathrm{H}_{2}\right)$, PUFA (C18:2), MUFA (C18:1), and SFA (C18:0).

$\frac{\partial c_{i}}{\partial t}+\nabla \cdot\left(-D_{i-o i l} \nabla c_{i}\right)+\mathbf{u} \cdot \nabla c_{i}=0$

Regarding the diffusion coefficient of hydrogen in edible oil, Fillion and Morsi (2000) proposed modifying the equation of Wilke and Chang (1955) by optimizing the power exponent for the viscosity $\left(n_{1}\right)$ and the solvent association parameter $(\Theta)$ using available data from the literature (see Eq. (26)):

$D_{H_{2}-o i l}=\frac{1.858 \times 10^{-15}\left(\Theta M_{o i l}\right)^{0.5} T}{\mu_{L}^{n_{1}} V_{A}^{0.6}}$

$D_{T A G-o i l}=\frac{A T}{\mu_{L}^{n_{2}}}$

where $M_{o i l}$ is the molecular weight of the oil in $\mathrm{kg} / \mathrm{kmol}$, $\mathrm{T}$ is the temperature in $K, \mu_{L}$ is the viscosity of the oil in Pa.s, and $V_{A}$ is the molar volume of hydrogen at its boiling temperature $\left(0.0143 \mathrm{~m}^{3} / \mathrm{kmol}\right)$. $\Theta$ and $n_{1}$ are the parameters optimized by Fillion and Morsi (2000). In the present work, the authors used data for diffusivity coefficients from the literature (Andersson et al., 1974, Andersson and Berglin, 1982, Ganguli and Berg, 1978, Gut et al., 1979), but more accurate viscosity values could be obtained with the developed model. Indeed, this viscosity model was optimized for the same type of oils used for the respective diffusivity measurements, by taking complementary experimental data for the fitting (Gupta et al., 2007, Ganguli and Berg, 1978, Hasenhuettl, 2000). $\Theta$ and $n_{1}$ were found to be 42 and 0.4 , respectively.

Fatty acids are combined in TAG molecules, whose diffusivity is considered to take a fixed value, regardless of the content of C18:2, C18:1, and C18:0 fatty acids. Therefore, a unique coefficient $D_{\text {TAG-oil }}$ given in Eq. (27) applies to all. In this equation, $A$ and $n_{2}$ are parameters optimized using data given by Andersson et al. (1974) and Gupta et al. (2007) as done for the hydrogen diffusivity. Their respective values are $7.72 \times 10^{-16}$ and 1.2 . Note that, in Case $2 \mathrm{~A}$, $D_{\mathrm{H}_{2} \text {-oil }}$ and $D_{\text {TAG-oil }}$ are defined locally because $\mu_{L}$ is also defined locally.

Table 9

Conditions of the simulations.

\begin{tabular}{|c|c|c|c|c|c|c|c|}
\hline$T(\mathrm{~K})$ & $p_{\mathrm{H}_{2}}($ bar,a) & $\mu_{0}$ (mPa.s) & $\sigma_{L}\left(\mathrm{mN} \cdot \mathrm{m}^{-1}\right)$ & $\rho_{L}\left(\mathrm{~kg} \cdot \mathrm{m}^{-3}\right)$ & $x_{C 18: 2,0}(\% \mathrm{~mol})$ & $x_{C 18: 1,0}(\% \mathrm{~mol})$ & $x_{C 18: 0,0}(\% \mathrm{~mol})$ \\
\hline 373.15 & 30 & 6.7 & $25.4^{\mathrm{a}}$ & $850^{\mathrm{b}}$ & 60 & 30 & 10 \\
\hline
\end{tabular}

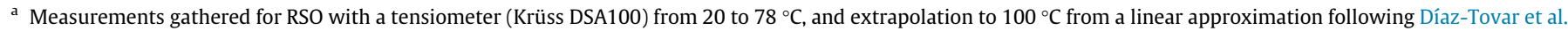
(2011).

b Measurements gathered for RSO with a densimeter (Anton Paar $4100 \mathrm{M}$ ) at $100{ }^{\circ} \mathrm{C}$. 


\subsubsection{Boundary conditions}

Hydrodynamics. The wall velocity is fixed to the bubble velocity, which was calculated in the course of the reaction using Eq. (19) and implicit evaluation of $\epsilon_{G}$ during calculation. Slip boundary conditions were set at the gas-liquid interface. Periodic boundary conditions were enforced for the velocity profiles, meaning the velocity profiles are identical at the top and bottom boundaries. A constant pressure difference is imposed between these boundaries $(\Delta P)$, whose value is determined using the open unit cell method developed by Durán Martínez et al. (2016). The validity of such an approach is discussed later.

Mass transfer. Regarding the hydrodynamics, periodic boundary conditions are defined for the mass transport equation, causing the concentration profiles to be the same at the inlet and outlet of UC. A zero-flux condition is imposed for fatty acids at the bubble surface due to their negligible vaporization. Dirichlet boundary condition are defined at this interface for hydrogen, where the dissolved concentration is equal to the concentration at saturation $\left(\mathrm{C}_{\mathrm{H}_{2}}^{*}\right)$ given by Eq. (28) from Fillion et al. (2002). One should note that the solubility of hydrogen in oil remained constant during hydrogenation (Vibrans, 1935; Andersson et al., 1974):

$c_{\mathrm{H}_{2}}^{*}=11.43 e^{\frac{-5000}{R T}} p_{\mathrm{H}_{2}}$

where $p_{H_{2}}$ is the gas pressure. Fluxes at the channel wall account for hydrogen consumption and the reaction of the three fatty acids considered here. The catalyst washcoat is considered thin enough to neglect any internal diffusion limitation in the layer depth, $\delta_{c}$; therefore, the catalytic layer is reduced to an equivalent active surface in the model. Reaction fluxes at the wall $\phi_{W, i}$ are given in Eq. (29), which accounts for the amount of catalyst per unit of wall surface; $r_{i}$ is the consumption/production rate of $\mathrm{H}_{2}, \mathrm{C} 18: 2, \mathrm{C} 18: 1$, and $\mathrm{C} 18: 0 ; \rho_{S}$ is the apparent alumina density and $w_{P d}$ is the mass fraction of palladium in the catalyst.

$\phi_{W, i}=r_{i} \delta_{c} \rho_{S} w_{P d}$

Consumption/production rates of $r_{i}$ follow the overall reaction scheme in Eq. (22) and are defined in Eqs. (30)-(33):

$r_{\mathrm{H}_{2}}=-\left(r_{1}+r_{2}\right)$

$r_{\mathrm{C} 18: 2}=-r_{2}$

$r_{\mathrm{C} 18: 1}=r_{2}-r_{1}$

$r_{\mathrm{C} 18: 0}=r_{1}$

where $r_{1}$ and $r_{2}$ are the reaction rates of consecutive hydrogenation steps 2 and 1, respectively. These rates are described by kinetic laws available in the literature (Fernández et al., 2007) for a $\mathrm{Pd} / \gamma(\mathrm{N})$ $\mathrm{Al}_{2} \mathrm{O}_{3}$ type catalyst, as defined in Eqs. (34) and (35).

$r_{2}=k_{2} \theta_{D} \theta_{H}$

$r_{1}=k_{1} \theta_{M} \theta_{H}$

The constants $k_{1}$ and $k_{2}$ obey the Arrhenius equation (Fernández et al., 2007). $\theta_{D}$ and $\theta_{M}$ are the fractional surface coverage of C18:2 and C18:1, respectively, on the catalyst surface. Fernández et al. (2007) assumed that the number of vacant sites for triglycerides was negligible, which results in unphysical values at high double bond conversion (MUFA fractional coverage, $\theta_{M}$, exceeding one). Subsequently, the $\theta_{D}$ and $\theta_{M}$ expressions were modified by considering vacant sites. Arbitrarily setting the value of the adsorption constant of $\mathrm{C} 18: 1 K_{M}$ to 1 in their expression adds a unity term to the denominator (this term remains negligible at high concentrations of unsaturated fatty acids, but it provides mathematical coherence at low concentrations; see Eqs. (36) and (37)).

$$
\begin{aligned}
\theta_{D} & =\frac{2 C_{C 18: 2}}{1+2 C_{C 18: 2}+C_{C 18: 1}+K_{S} / K_{M} \cdot C_{C 18: 0}} \\
\theta_{M} & =\frac{C_{C 18: 1}}{1+2 C_{C 18: 2}+C_{C 18: 1}+K_{S} / K_{M} \cdot C_{C 18: 0}} \\
\theta_{H} & =\frac{\sqrt{K_{H} C_{H_{2}}}}{1+\sqrt{K_{H} C_{H_{2}}}}
\end{aligned}
$$

Fractional surface coverage for $\mathrm{H}_{2} \theta_{H}$ is based on dissociative adsorption of hydrogen (see Eq. (38)). $\theta_{D}, \theta_{M}$, and $\theta_{H}$ are functions of the local concentrations in the catalyst pores.

\subsubsection{Useful deduced parameters}

The molar flow rate of transferred hydrogen $\Phi_{B, H_{2}}$ at the bubble interface is determined from the integral of the diffusive flux over the overall gas-liquid surface using Eq. (39). The molar flow rate of any fatty acid at the wall is given by Eq. (40) (where $F A_{i}$ is C18:2, C18:1, or C18:0).

$\Phi_{B, H_{2}}=\iint_{\text {bubble }}-D_{\mathrm{H}_{2}-\text { oil }}\left(\frac{\partial c_{\mathrm{H}_{2}}}{\partial z} \cdot n_{z}+\frac{\partial c_{\mathrm{H}_{2}}}{\partial r} \cdot n_{r}\right) d S_{B}$

$\Phi_{W, F A_{i}}=\iint_{\text {wall }}-D_{T A G-o i l}\left(\frac{\partial c_{F A_{i}}}{\partial z} \cdot n_{z}+\frac{\partial c_{F A_{i}}}{\partial r} \cdot n_{r}\right) d S_{W}$

The volume averaged concentration of a given chemical species $c_{i, \text { overall }}$ is shown in Eq. (41).

$c_{i, \text { overall }}=\frac{\iiint_{V_{L}} c_{i} d V}{\iiint_{V_{L}} d V}$

The overall volumetric gas-liquid mass transfer coefficients $k_{G L} a_{G L}$ are calculated using Eq. (42).

$k_{G L} a_{G L}=\frac{\Phi_{B, H_{2}}}{c_{H_{2}}^{*}-c_{H_{2}, \text { overall }}} \frac{1}{V_{U C}}$

The overall volumetric liquid-solid mass transfer coefficients are defined in Eq. (43).

$k_{L S} a_{L S}=\frac{\Phi_{W, F A_{i}}}{c_{F A_{i}, \text { overall }}-c_{F A_{i}, \text { wall }}} \frac{1}{V_{U C}}$

These calculated mass transfer coefficients can be compared with the correlations established by van Baten and Krishna (2004) for $k_{G L} a_{G L}$ and Hatziantoniou and Andersson (1982) for $k_{L S} a_{L S}$, shown in Eqs. (44)-(46). Geometric characteristics $R_{B}$ (bubble radius), $L_{U C}$ (unit cell length), $L_{f}$ (lubrification film length), and $d_{c}$ (channel diameter) are given or deduced from Table $10 . R e_{L}$ is the liquid Reynolds number (Eq. (47)) and $S c_{L}$ is the Schmidt number for triglycerides (Eq. (48)). Note that average values for diffusivity and viscosity were used in Case 2A.

$$
\begin{aligned}
& k_{G L}=\frac{2 \sqrt{2}}{\pi} \sqrt{\frac{D_{H_{2}-\text { oil }} U_{B}}{d_{c}}} \\
& a_{G L}=\frac{4 \pi R_{B}^{2}+2 \pi R_{B} L_{f}}{\pi\left(d_{c} / 2\right)^{2} L_{U C, 0}} \\
& k_{L S} a_{L S}=3.51 R e_{L}^{0.446} S c_{L}^{0.441}\left(\frac{L_{U C}}{d_{c}}\right)^{-0.449}\left(\frac{L_{U C}-L_{f}}{d_{c}}\right)^{-0.087}
\end{aligned}
$$

Table 10

Unit cell geometry.

\begin{tabular}{cccc}
\hline$d_{c}$ & $L_{U C, 0}$ & $\delta_{f}$ & $\epsilon_{G, 0}$ \\
\hline $3 \mathrm{~mm}$ & $40 \mathrm{~mm}$ & $47 \mu \mathrm{m}$ & $60 \%$ \\
\hline
\end{tabular}


$\operatorname{Re}_{L}=\frac{\rho_{L} d_{c} u_{L S}}{\mu_{L}}$

$S c_{L}=\frac{\mu_{L}}{\rho_{L} D_{\text {TAG-oil }}}$

\subsubsection{Geometry, meshing, and numerical parameters}

As previously discussed, the geometry of the bubble consists of a cylindrical body with hemispheres at both ends, which was inspired by van Baten and Krishna (2004). The liquid film thickness $\delta_{f}$ is calculated using Eq. (21) for a given cylindrical channel diameter $d_{c}$ and the liquid properties (Table 9). These values are given along with the inlet values of the gas hold-up $\epsilon_{G, 0}$, and length of the UC $L_{U C, 0}$, in Table 10.

Note that the latter parameter cannot be determined a priori as it depends on the channel feeding technology. A realistic order of magnitude was chosen in this study.

Special care must be taken to ensure appropriate meshing resolution in the CFD simulation for Taylor flow, especially near the wall and at the gas-liquid interface, where the velocity and radial concentration gradients are localized (in particular in the liquid lubricating film). Moreover, a high Peclet number due to very low TAG diffusivity $\left(\mathrm{O}\left(10^{-10} \mathrm{~m}^{2} \mathrm{~s}^{-1}\right)\right.$, see Eq. (27)) and high axial velocity near the wall may create resolution instabilities, hence the axial mesh distribution must be adequate as well. A poor meshing resolution could indeed inhibit an accurate description of the velocity and concentration fields (Gupta et al., 2009; Durán Martínez et al., 2016).

Free triangular meshing was used near the bubble hemispheres, while mapped meshing was applied in the film and slugs; finally, boundary layer meshing was defined at the wall and gas-liquid interface (see Fig. 7). The meshing distribution was adjustable in mapped cell domains, maximal and minimal element sizes in the free cell domains, and at boundaries. Furthermore, in order to obtain accurate results, a quadratic polynomial approximation was used for the velocity calculation, and a linear function was used for pressure calculation. A cubic polynomial was used for concentration field processing. The relative tolerance was set to $10^{-3}$. A sensitive study of the mesh size was conducted to ensure the correct resolution was used. Time-dependent simulations were performed at constant viscosity (hence constant diffusivities) until the stop criterion was met. The final composition and total traveled distance $z_{f}$ (found by time integration of $U_{T P}$ ) for different meshing sizes were compared. The results are listed in Table 11; these values were obtained with a PC running Windows 1064 bit (Intel Xeon CPU W-2123 @ 3.60 GHz, 128 GB-RAM).

As a convergence plateau is nearly reached $(0.5 \%$ relative difference between Meshes \#4 and \#5, see Fig. 6), and as memory, computation time, and accuracy imply some compromises, meshes with 433,533 cells were used thereafter (Mesh \#5, shown in Fig. 7). As a comparison, 72,890 elements (van Baten and Krishna, 2004) and 77,318 elements (Durán Martínez et al., 2016) were used in previous studies.

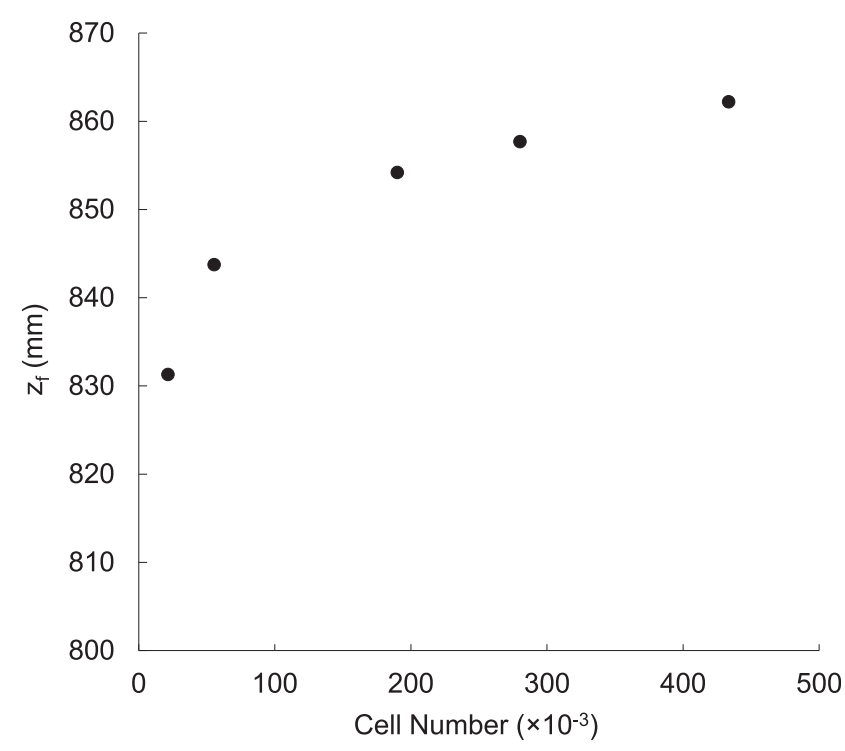

Fig. 6. Meshing convergence: final traveled distance $z_{f}$ as a function of cell number for Case $1 \mathrm{~A}$.

\subsection{Results and discussions}

\subsubsection{Approach assessment}

Hydrodynamics description of the flow for Case 1A. A hydrodynamics description in Taylor flow conditions was studied by Durán Martínez et al. (2016). The same characteristics were observed in this study: Hagen-Poseuille flow is retrieved in the major part of the liquid slug, while the condition for formation of velocity vortices (described in the literature for $\mathrm{Ca}<0.5$ ) is met (see Fig. 8). Inversion of the velocity profile between the slug and film is noticeable; such a phenomenon was documented in various papers (Durán Martínez et al., 2016; Abiev, 2011).

Slip boundary condition at the gas-liquid interface induces a low shear stress in the liquid film. Due to gas consumption, $U_{B}$ slows down during the calculation, which has a direct impact on the hydrodynamics of the slug and film (see Fig. 9), as well as on the traveling speed of the UC (see Fig. 10).

As $U_{B}$ varies as the bubble travels in channel, $\Delta P$ should also vary. In the literature, a constant value of $\Delta P$ is often used (van Baten and Krishna, 2004, Durán Martínez, 2017). However, the sensibility of the $\Delta P$ results was investigated in this study for two different values: $-400 \mathrm{~Pa}$ (from the open UC calculation, i.e., without the periodic condition, see Durán Martínez et al. (2016)) and 0 Pa. Hagen-Poiseuille flow in the liquid slug does not seem to be impacted, yet shear stress in the liquid film is reduced in the null pressure difference case, resulting in a $5.5 \%$ longer travel distance $z_{f}$. However, no variation in the outlet composition was observed compared to the $\Delta P=-400 \mathrm{~Pa}$ case. As stated later, this difference is rather small compared to that from Case $2 \mathrm{~A}$ (accounting for viscosity evolution); therefore, a constant pressure difference of $-400 \mathrm{~Pa}$ was used in the rest of the study.

Table 11

Mesh characteristics for sensitivity analysis.

\begin{tabular}{|c|c|c|c|c|c|c|}
\hline & Total cell number & $x_{C 18: 2}$ & $x_{C 18: 1}$ & $x_{C 18: 0}$ & $X_{f}$ & $z_{f}$ \\
\hline$\# 1$ & 21,597 & 40.4 & 21.8 & 37.8 & 31.6 & 831 \\
\hline$\# 2$ & 55,512 & 40.4 & 21.8 & 37.8 & 31.6 & 844 \\
\hline \#3 & 190,170 & 40.5 & 21.7 & 37.8 & 31.5 & 854 \\
\hline \#3 & 280,289 & 40.5 & 21.7 & 37.8 & 31.5 & 858 \\
\hline \#5 & 433,533 & 40.5 & 21.6 & 37.8 & 31.5 & 862 \\
\hline
\end{tabular}



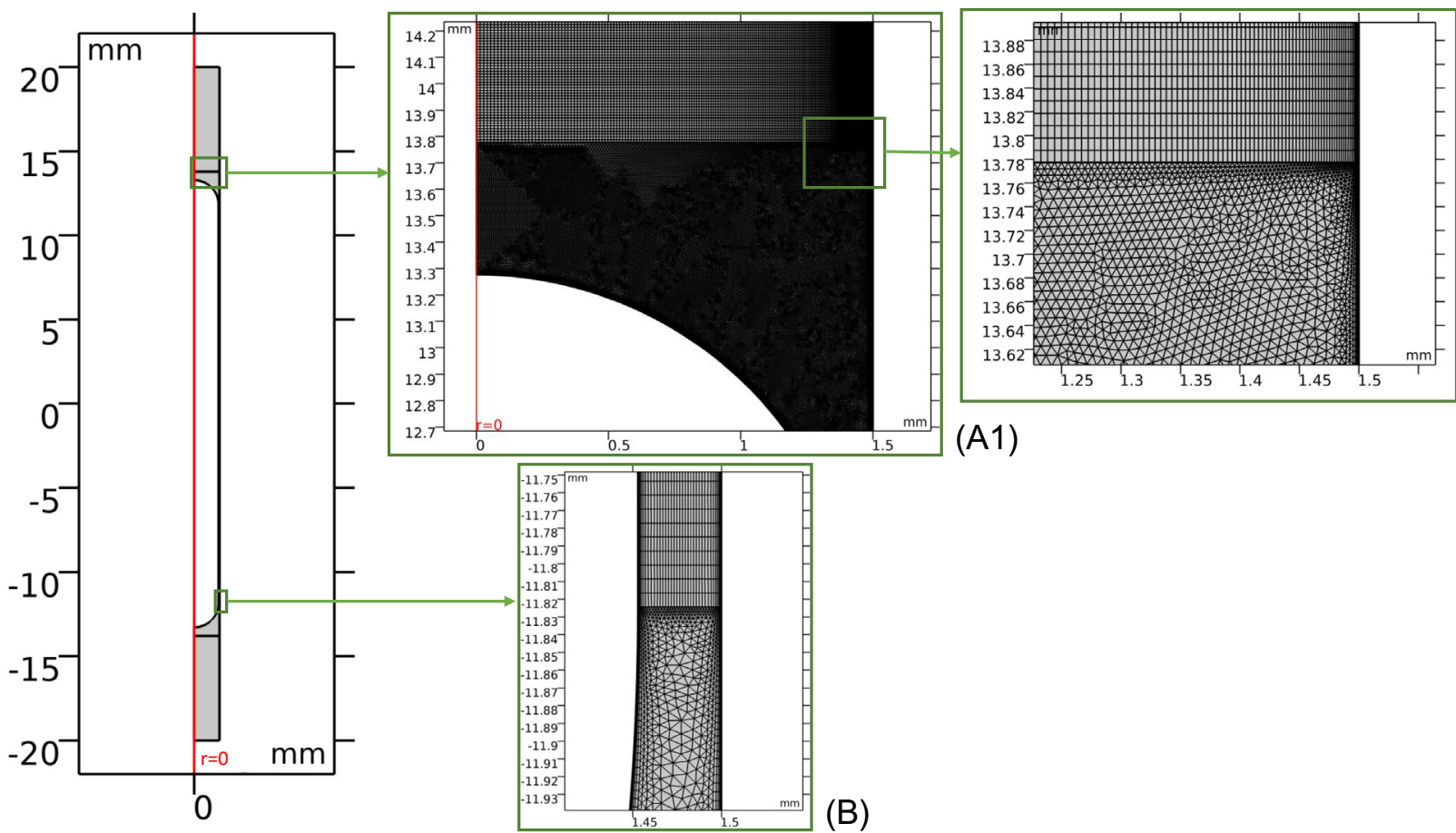

(A2)

(A1)

Fig. 7. Mesh \#5, zoomed into the junction between mapped quadrangle and free triangle domains: bubble cap - liquid slug (A1-A2), and bubble cap - liquid film (B).

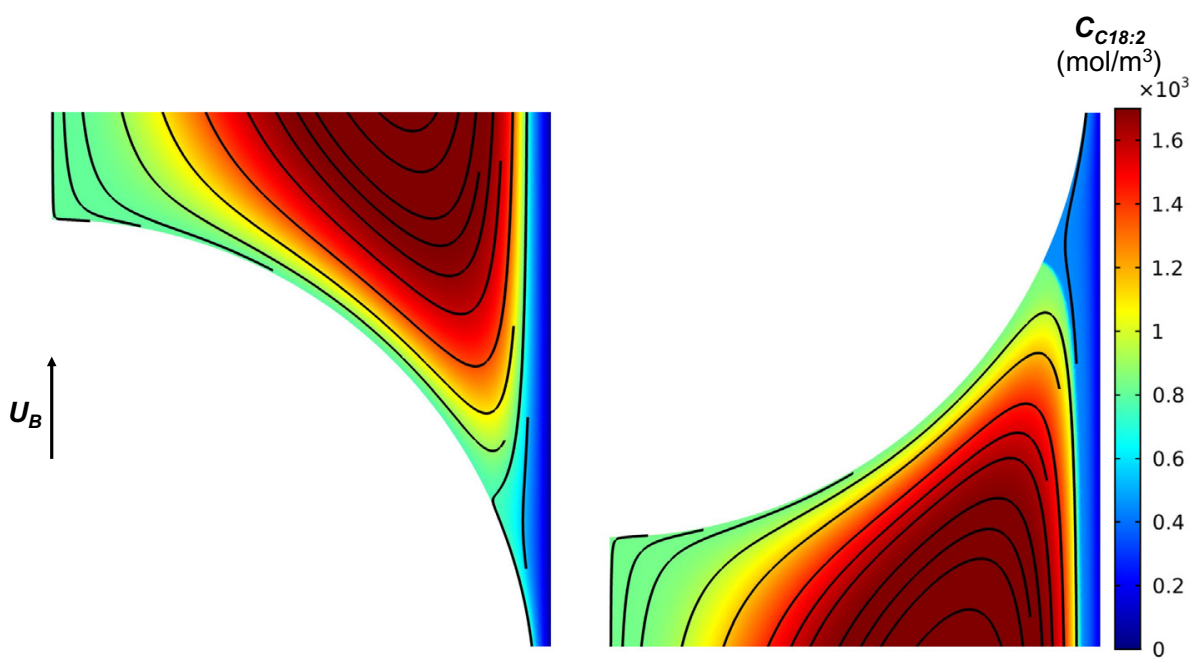

Fig. 8. PUFA concentration field and streamlines at the bubble top (left) and rear (right) for $z=0.45 z_{f}$, Case $1 \mathrm{~A}$.

Concentration field and reaction yield for Case 1A. Concentration fields for PUFA fatty acids at the mid-channel UC position $\left(z=0.45 z_{f}\right)$ are given in Fig. 8. Due to consumption of these species by the chemical reaction at the wall, sharp C18:2 concentration contrasts are noticeable between the near-wall regions and the rest of the liquid.

Mass transfer characteristics for Case 1A. A distinction must be made between the near-wall mass boundary layer and the rest of the liquid. Three consecutive zones can be distinguished when looking at the average concentrations of fatty acids at the wall $\left(r=R_{C}\right)$ (see Fig. 11):

1. C18:2 fatty acid initially present at the wall is quickly consumed and the C18:1 fatty acid concentration increases. This is due to the higher hydrogenation rate for PUFA compared to
MUFA (yielding SFA). Hydrogen supply at the wall quickly becomes the limiting phenomenon. The end of this zone occurs when the average concentration of MUFA peaks, which occurs very soon at $z_{1}=0.04 z_{f}$.

2. PUFA concentration near wall tends to zero while the MUFA concentration peaks, thus hydrogenation to SFA dominates. The MUFA concentration drops at the wall while the hydrogen concentration increases slowly, indicating the hydrogen supply is not limiting, in contrast to the previous zone.

3. In turn, the MUFA concentration tends to zero at position $z_{2}=0.45 z_{f}$. Diffusion of unsaturated fatty acids at the wall becomes the limiting step and the SFA concentration at the wall plateaus. Consequently, the hydrogen concentration at the wall and in the rest of liquid increases sharply (as observed in the $\mathrm{H}_{2}$ concentration field for $z>z_{2}$ ). 

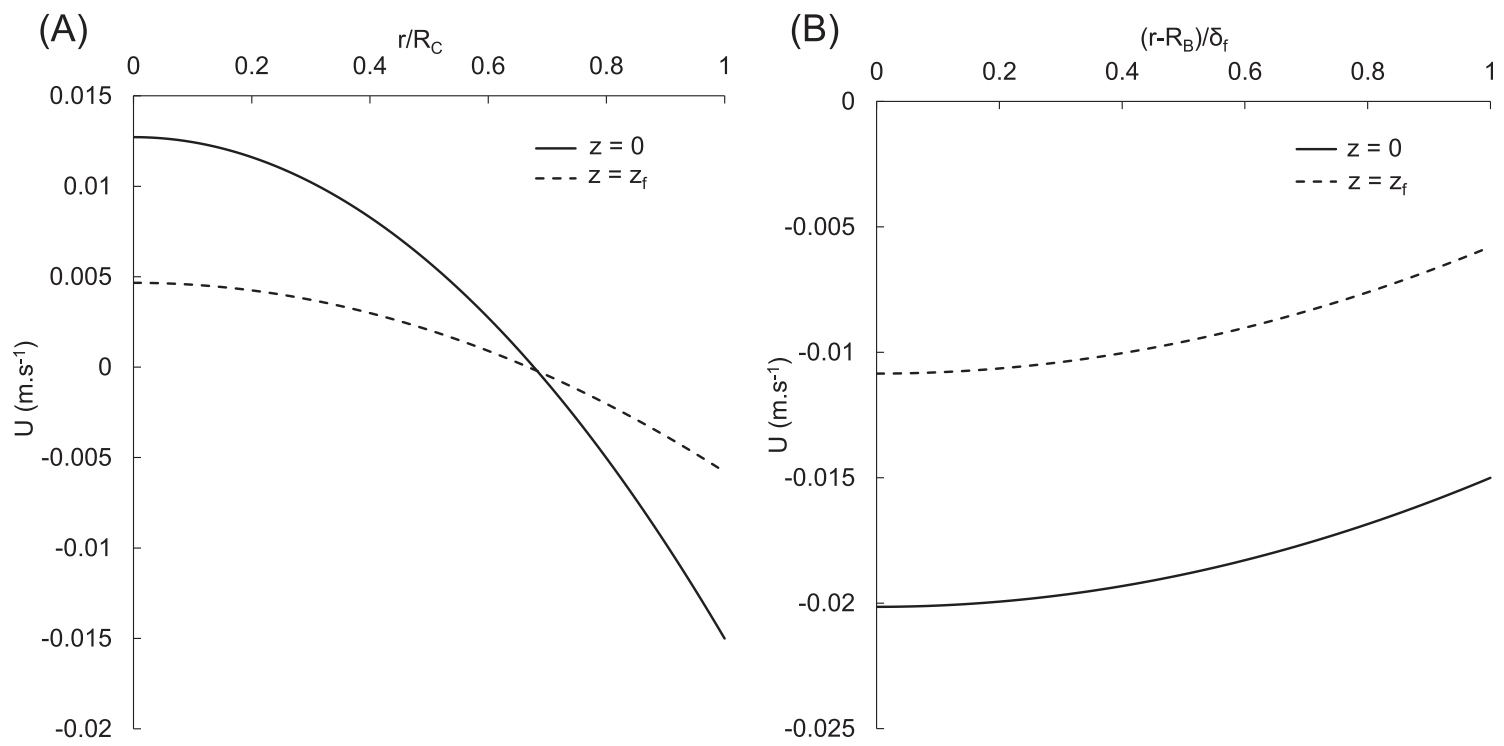

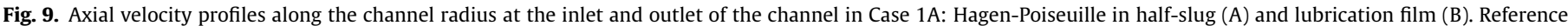
frame moving with the bubble, where the wall velocity is equal to $-U_{B}$.

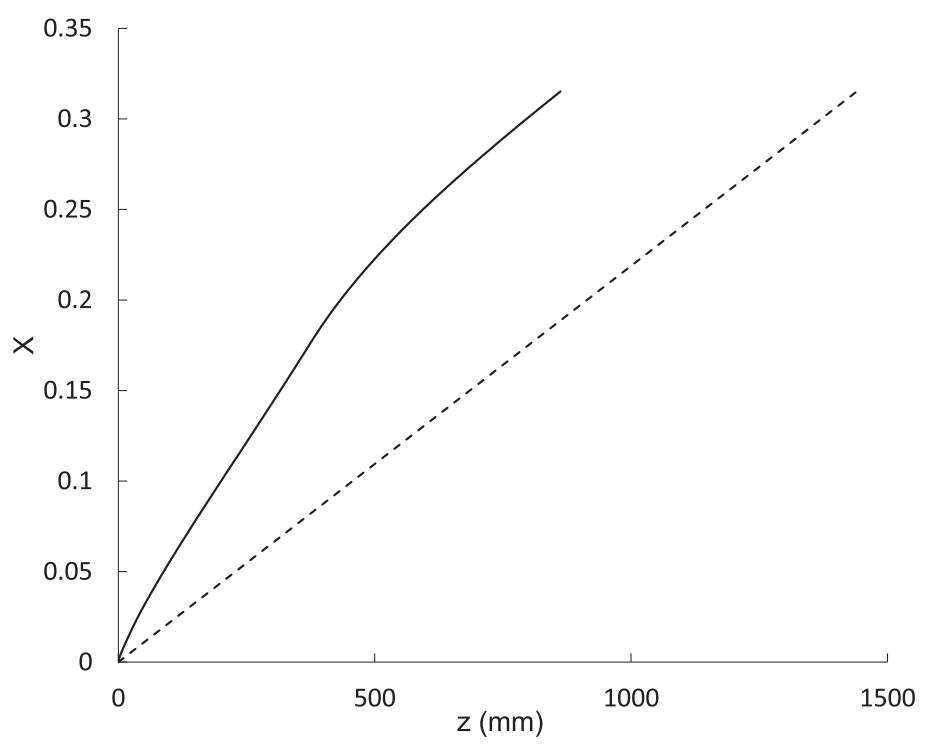

Fig. 10. Saturation degree $X$ as a function of the UC position $z$ for Case $1 \mathrm{~A}$, where $U_{B}$ is updated during calculation (-), $U_{B}$ constant (- -).

Thus, the PUFA hydrogenation rate is high, and the initially available C18:2 fatty acids at the wall are quickly consumed, resulting in a sharp gradient near the wall, as shown in Fig. 12. The C18:2 fatty acids present in the rest of the liquid slug supply the reaction to some extent as the slug vortex which enables PUFA present at the channel center to reach the near-wall region. The connection between these two areas is made through the top and rear of the bubble, as shown in Fig. 8. Conversely, the vortex center, which is a small liquid slug volume wedged between the center of the channel and the near-wall concentration gradient, remains at constant concentration throughout the channel due to the low shear rate and very low TAG diffusivity (the final PUFA concentration plateau remains equal to the initial concentration for $r / R_{C} \in[0.55 ; 0.8]$ in Fig. 12). This latter region is primarily diffusion-dominated (species diffuse perpendicular to the streamlines), and the common assumption that liquid slugs are wellmixed regions is refuted (Rhines and Young, 1983; Young et al., 1989; Yang et al., 2017; Nirmal et al., 2019; Butler et al., 2016).
Accordingly, C18:2 consumption at the entrance of the channel induces an increase in C18:1 concentration at the wall because the hydrogenation rate of PUFA is greater than that of MUFA (Fig. 12). This results in a slightly higher than initial C18:1 concentration in the channel center thanks to the slug vortex until a given C18:2 depletion threshold is reached. Freshly produced C18:1 fatty acids are subsequently hydrogenated into saturated C18:0 fatty acids. The radial PUFA and MUFA concentration profiles eventually exhibit the same characteristics.

It is shown that the transfer limitation of TAG from the bulk liquid to the wall appears quickly, resulting in a low C18:1 concentration at the outlet (see $x_{\mathrm{C} 18: 1}$ molar fraction in Table 11 for Mesh \#5).

Impact of the viscosity evolution in Cases $1 \mathrm{~A}$ and $2 \mathrm{~A}$. Case $2 \mathrm{~A}$ uses the same geometry and meshing characteristics as in Case $1 \mathrm{~A}$. While the initial diffusivity coefficients and viscosity are identical in both cases, Case 2A accounts for changes in viscosity (and therefore in diffusivities) due to the increased saturation degree along the channel, with the help of the developed viscosity model. 


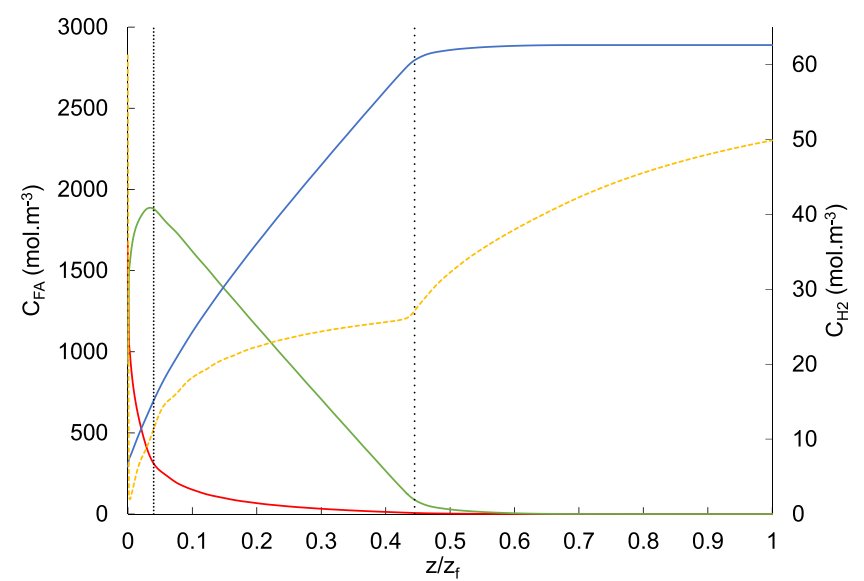

Fig. 11. Average FA and hydrogen concentrations at the wall as a function of the relative UC position $z / z_{f}$ for Case 1A: C18:2 (red), C18:1 (green), C18:0 (blue), $\mathrm{H}_{2}$ (yellow dashes - second axis). Coordinates $z_{1} / z_{f}(\cdots)$ and $z_{2} / z_{f}(--)$ represented. (For interpretation of the references to color in this figure legend, the reader is referred to the web version of this article.)

The distribution of fatty acids at the outlet, total channel length $z_{f}$, and final saturation degree $X_{f}$ for Cases $1 \mathrm{~A}$ and $2 \mathrm{~A}$ are compared in Table 12 . While fatty acid fractions are only slightly impacted with slightly lower MUFA fraction in Case 2A, the total channel length $z_{f}$ is $45 \%$ longer.

Table 13 shows the average diffusivities and viscosity, as well as their minimal and maximal values in the liquid, between the inlet and the outlet of the channel for Case 2A. It can be observed that the average viscosity increases by $23 \%$, while the hydrogen and TAG diffusivities decrease by $7 \%$ and $18 \%$, respectively.

Fig. 13 shows the saturation degree field in the outlet liquid. As expected, saturation is high near the wall where the reactions occur. This induces a viscosity gradient, which affects the velocity in the slug and in the film compared to Case 1A (see Fig. 14). A slight deviation from the Hagen-Poiseuille velocity is noticeable in the slug, while high viscosity in the film reduces the shear rate. Note that $\Delta P$ in Case $2 \mathrm{~A}$ is chosen constant and equal to that in Case $1 \mathrm{~A}(-400 \mathrm{~Pa})$.

In addition, the high values of viscosity near the wall generate low values of diffusivities in that region, hindering fresh reactants
Table 12

Distribution of fatty acids at the outlet, saturation degree, and total channel length in Cases $1 \mathrm{~A}$ and $2 \mathrm{~A}$.

\begin{tabular}{cccccc}
\hline Case number & $x_{C 18: 2}$ & $x_{C 18: 1}$ & $x_{C 18: 0}$ & $X_{f}{ }^{a}$ & $z_{f}$ \\
\hline $1 \mathrm{~A}$ & 40.5 & 21.6 & 37.8 & 31.5 & 862 \\
2A & 40.8 & 21.4 & 37.8 & 31.4 & 1254 \\
\hline
\end{tabular}

a The small variation in $X_{f}$ is due to a different dissolved hydrogen quantity in the liquid (different concentration fields) at $z_{f}$.

Table 13

Changes in viscosity and diffusivity coefficient between the inlet and outlet of the channel in Case 2A.

\begin{tabular}{ccc}
\hline Physical properties & Inlet $(z=0)$ & Outlet $\left(z=z_{f}\right)$ \\
\hline$\mu_{L, \text { ave }}(\mathrm{mPa} \mathrm{s})$ & 6.7 & 8.3 \\
$\mu_{L, \text { min }}(\mathrm{mPa} \mathrm{s})$ & - & 6.7 \\
$\mu_{L, \text { max }}(\mathrm{mPa} \mathrm{s})$ & - & 12.2 \\
$D_{\mathrm{H}_{2} \text {-oil,ave }}\left(\mathrm{m}^{2} \mathrm{~s}^{-1}\right)$ & $1.26 \times 10^{-8}$ & $1.17 \times 10^{-8}$ \\
$D_{\mathrm{H}_{2} \text {-oil,min }}\left(\mathrm{m}^{2} \mathrm{~s}^{-1}\right)$ & - & $9.95 \times 10^{-9}$ \\
$D_{\mathrm{H}_{2} \text {-oil,max }}\left(\mathrm{m}^{2} \mathrm{~s}^{-1}\right)$ & - & $1.26 \times 10^{-8}$ \\
$D_{\text {TAG-oil,ave }}\left(\mathrm{m}^{2} \mathrm{~s}^{-1}\right)$ & $1.16 \times 10^{-10}$ & $9.54 \times 10^{-11}$ \\
$D_{T A G-\text { oil,min }}\left(\mathrm{m}^{2} \mathrm{~s}^{-1}\right)$ & - & $5.70 \times 10^{-11}$ \\
$D_{\text {TAG-oil,max }}\left(\mathrm{m}^{2} \mathrm{~s}^{-1}\right)$ & - & $1.16 \times 10^{-10}$ \\
\hline
\end{tabular}

in the bulk from reaching the wall, and inhibiting newly produced species from reaching the slug. This increases mass transfer limitation effects, thus inducing a longer required channel length to reach a similar reaction yield.

As presented for Case 1A in Fig. 11, Fig. 15 displays average concentrations at the wall for fatty acids along the length of the channel. Case $2 \mathrm{~A}$ shows the same characteristic zones as described in Case 1A, however second and third zones appear earlier (Table 14). These limitations are due to reduced TAG diffusivity and higher viscosity, especially near the wall. Note that the transport of PUFA and MUFA are similarly affected because they share the same diffusivity within TAG. Subsequently, the distribution of fatty acids at the outlet is nearly identical in Cases $1 \mathrm{~A}$ and $2 \mathrm{~A}$, as was previously mentioned (see Table 12).

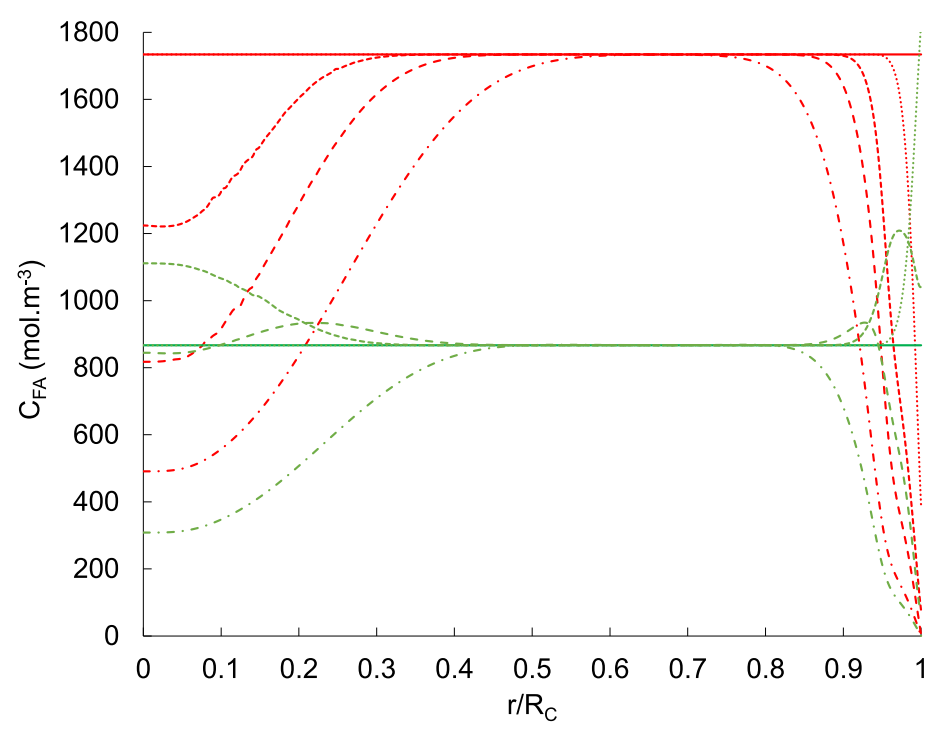

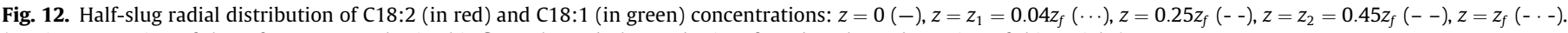
(For interpretation of the references to color in this figure legend, the reader is referred to the web version of this article.) 


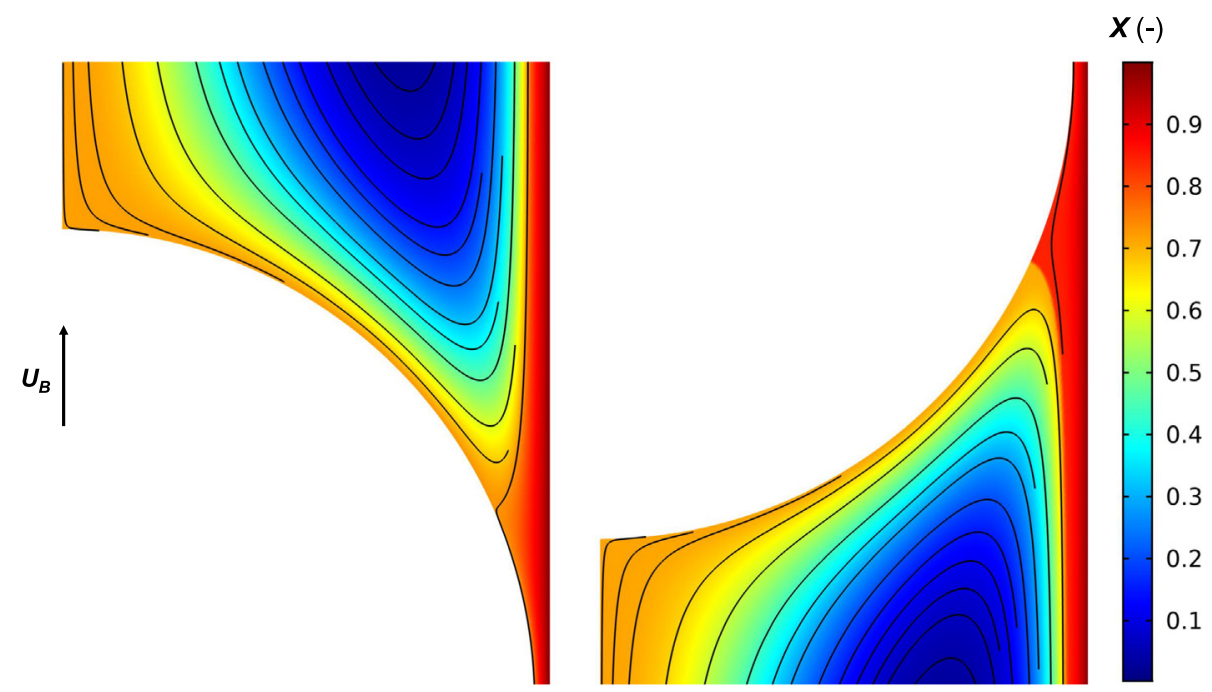

Fig. 13. Saturation degree $X$ field and streamlines at the bubble top (left) and rear (right) for $z=z_{f}$ in Case $2 A$.

\section{(A)}

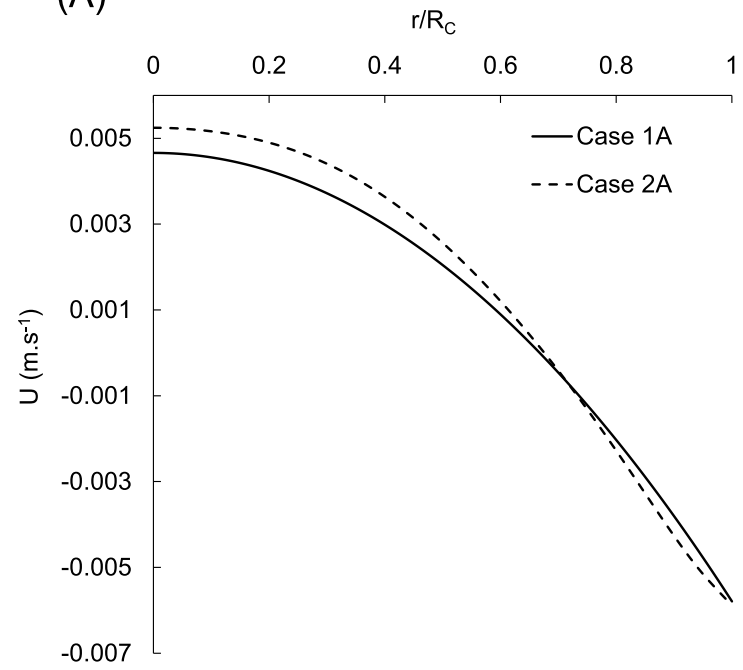

(B)

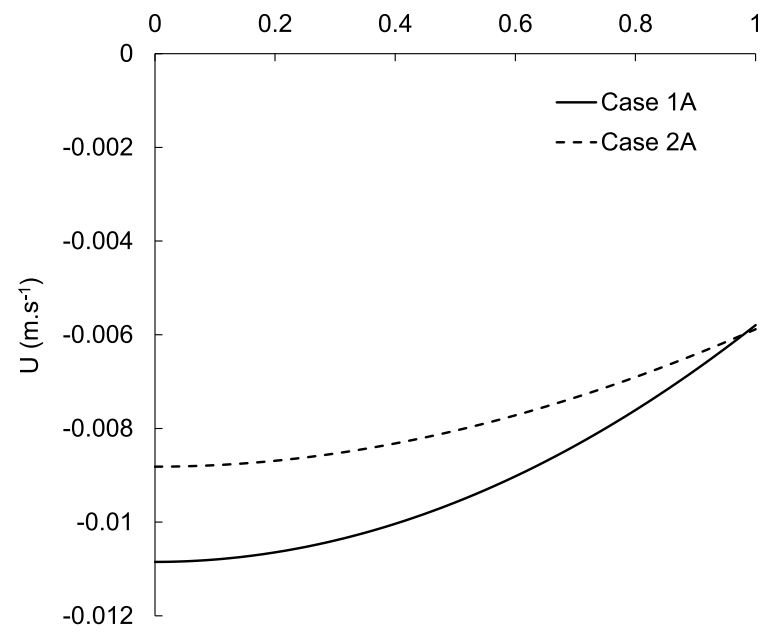

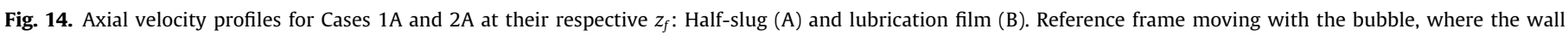
velocity is equal to $-U_{B}$.

The mass transport of species between the gas and liquid slug, and the slug and lubrication film, are crucial points determining hydrogenation in Taylor flow.

The volumetric gas-liquid mass transfer coefficient $k_{G L} a_{G L}$ can be estimated with Eq. (42) and the correlation from van Baten and Krishna (2004) established from CFD simulations (Eqs. (44) and (45)). Both estimates are in good agreement until the regime where PUFA and MUFA transfer becomes limited at the wall (third zone). Conversely, when the hydrogen concentration increases at the wall and in the liquid bulk, the simulation shows a drop in $k_{G L} a_{G L}$ in Cases $1 \mathrm{~A}$ and $2 \mathrm{~A}$ (Fig. 16), resulting in $38 \%$ and $58 \%$ relative differences at the outlet, respectively, when compared to van Baten and Krishna (2004) correlation. It should be recalled that only the variation in $k_{G L}$ was accounted for in the simulation.

Fig. 17 shows the volumetric liquid-solid mass transfer coefficient $k_{L S} a_{L S}$ evaluated for C18:2 fatty acid in Cases 1A and 2A using Eq. (43). Note that this coefficient is a local parameter and can evolve along the channel together with concentration, reaction rate, and unit cell volume. The coefficient $k_{L S} a_{L S}$ in Taylor flow is also evaluated using the correlation of Hatziantoniou and Andersson (1982) determined from dissolution experiments (see

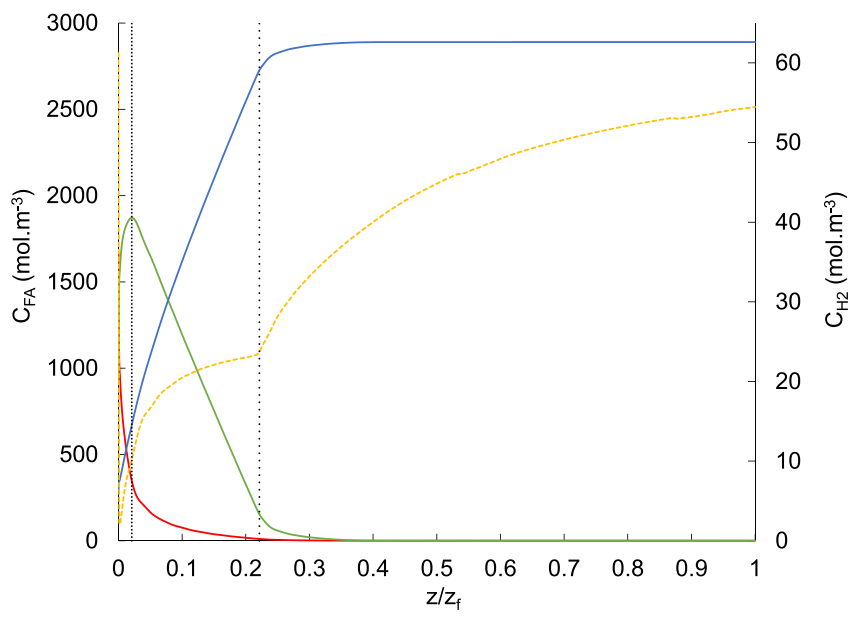

Fig. 15. Average FA and hydrogen concentrations at the wall as a function of the relative UC position $z / z_{f}$ for in Case 2A: C18:2 (red), C18:1 (green), C18:0 (blue), $\mathrm{H}_{2}$ (yellow dashes - second axis). Coordinates $z_{1} / z_{f}(\ldots)$ and $z_{2} / z_{f}(--)$ represented. (For interpretation of the references to color in this figure legend, the reader is referred to the web version of this article.) 
Table 14

Location of regime transition in Cases $1 \mathrm{~A}$ and $2 \mathrm{~A}$.

\begin{tabular}{ccc}
\hline & Case $1 \mathrm{~A}$ & Case $2 \mathrm{~A}$ \\
\hline$z_{1}$ & $30 \mathrm{~mm}\left(0.04 z_{f}\right)$ & $26 \mathrm{~mm}\left(0.02 z_{f}\right)$ \\
$z_{2}$ & $388 \mathrm{~mm}\left(0.45 z_{f}\right)$ & $278 \mathrm{~mm}\left(0.22 z_{f}\right)$ \\
\hline
\end{tabular}

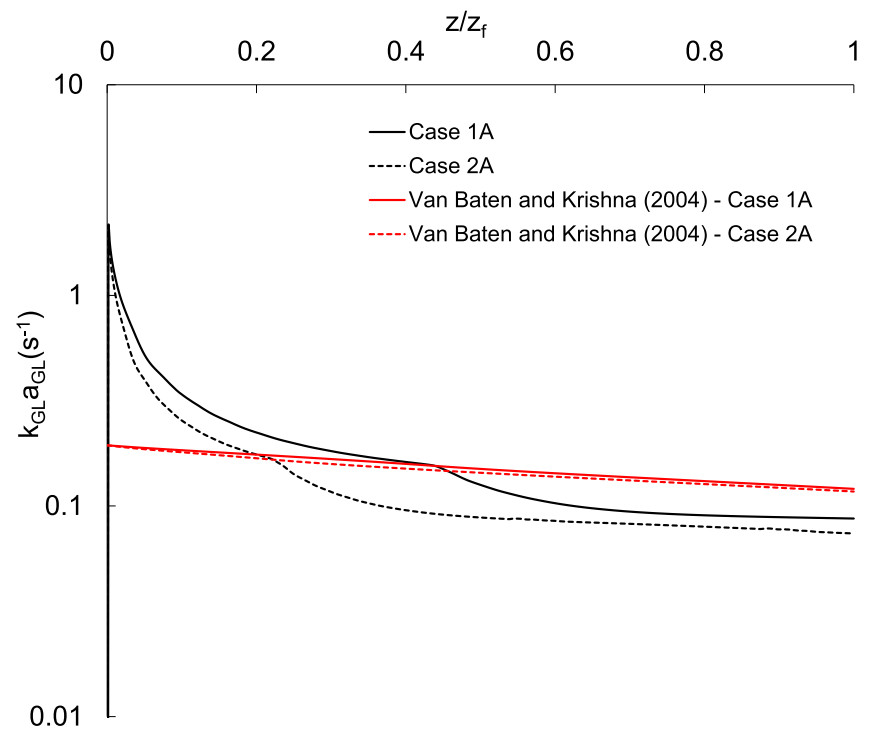

Fig. 16. Gas-liquid mass transfer coefficient $k_{G L} a_{G L}$ for Cases $1 \mathrm{~A}$ and $2 \mathrm{~A}$ calculated using Eq. (42) and estimated with the correlation of van Baten and Krishna (2004).

Eq. (46)), in which the possible effects of the reaction are absent. As expected, $k_{L S} a_{L S}$ drops faster along the channel in Case $2 \mathrm{~A}$ than in Case $1 \mathrm{~A}$ due to changes in viscosity and diffusivity, leading to a $37 \%$ relative difference in the coefficient values at the outlet between the two cases. The values obtained with the aforementioned correlation (Hatziantoniou and Andersson, 1982) are identical in both cases. At the entrance, where gradients at the wall have not yet been established, the values determined with the correlation and numerical simulation are of the same order of magnitude, while at the outlet of the channel, the correlation clearly overestimates $k_{L S} a_{L S}$ by a factor 12 and 19 in Cases $1 \mathrm{~A}$ and $2 \mathrm{~A}$, respectively.
Such an observation was already reported in the literature (Durán Martínez, 2017).

Sensitivity of the TAG diffusion coefficient. The clear limitation in TAG transfer at the channel wall is evidence of very low diffusion coefficient values. This situation worsens when taking into account viscosity changes. Considering possible uncertainties in TAG diffusivity found in the literature (with values varying by a factor 5 (Gut et al., 1979, 1974)), a sensitivity study on this parameter was conducted by repeating the simulations for Cases $1 \mathrm{~A}$ and $2 \mathrm{~A}$ with $D_{\text {TAG-oil }}$ increased by a factor of 5 . These two new Cases are noted 1B (no viscosity evolution) and 2B (viscosity evolution).

Table 15 shows the outlet average composition and physical properties in Cases $1 \mathrm{~A}$ and $1 \mathrm{~B}$, then in Cases 2A and 2B. The influence of the TAG diffusion coefficient on composition and channel length is evident: $z_{f}$ decreases by $40 \%$ between Cases $1 \mathrm{~A}$ and $1 \mathrm{~B}$ and by $35 \%$ between Cases $2 \mathrm{~A}$ and $2 \mathrm{~B}$. The distribution of fatty acids is clearly affected by the diffusivity increase, which leads to a greater MUFA molar fraction at the outlet.

When looking at the average PUFA and MUFA molar concentrations at the wall in all cases (Fig. 18 (B)), the third zone described in Case $1 \mathrm{~A}$ is never reached in Cases $1 \mathrm{~B}$ and $2 \mathrm{~B}$. However, the TAG transfer limitation can still be seen in both cases because the MUFA peak concentration is seen at the wall (see a comparison of Figs. 18 (A) and (B)), meaning that PUFA transfer to the wall still hinders the reaction.

The evolution of $k_{G L} a_{G L}$ in Cases 1B and 2B is shown in Fig. 19. Because the third zone is never reached here, the decreases noticed in Cases $1 \mathrm{~A}$ and $2 \mathrm{~A}$ (Fig. 16) are absent, leading to only $19 \%$ and $13 \%$ of relative deviation from the correlation given by van Baten and Krishna (2004).

The volumetric liquid-solid mass transfer coefficient in Case 1B is one order of magnitude larger than that in Case 1A (Figs. 17 and 20). Furthermore, $k_{L S} a_{L S}$ at the outlet is $71 \%$ lower in Case $2 \mathrm{~B}$ than in Case 1B, meaning that the influence of the viscosity evolution on the liquid-solid mass transfer coefficient is stronger than in Cases $1 \mathrm{~A}$ and 2A. Nevertheless, because the TAG transfer to the wall is less limiting in Cases $1 \mathrm{~B}$ and $2 \mathrm{~B}$ (zone 3 is never reached), the sharp decrease in $k_{L S} a_{L S}$ in the latter two cases only has a moderate impact on the final fatty acid composition.

Finally, Fig. 21 shows the evolution of PUFA and MUFA molar fractions versus saturation degree $X$ for all considered cases and an ideal scenario neglecting both external and intraparticular mass transfer limitations. In this case, the evolution of the species was solved by assuming a plug flow behavior with uniform

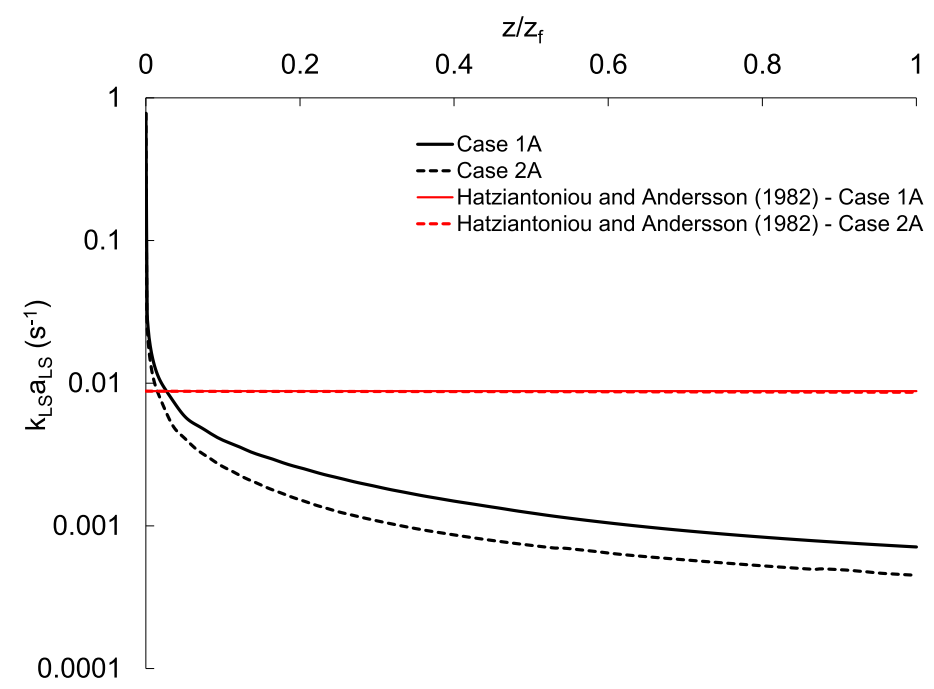

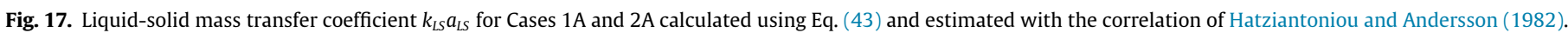


Table 15

Physical properties, composition at the outlet, and channel length comparison for Cases 1A, 2A, 1B, and $2 \mathrm{~B}$.

\begin{tabular}{|c|c|c|c|c|}
\hline Case & $1 \mathrm{~A}$ & $1 \mathrm{~B}$ & $2 \mathrm{~A}$ & $2 \mathrm{~B}$ \\
\hline$\mu_{L, a v e}(\mathrm{mPa} \mathrm{s})$ & 6.7 & 6.7 & 8.3 & 8.3 \\
\hline$D_{\mathrm{H}_{2}-\text { oillave }}\left(\mathrm{m}^{2} \mathrm{~s}^{-1}\right)$ & $1.26 \times 10^{-8}$ & $1.26 \times 10^{-8}$ & $1.17 \times 10^{-8}$ & $1.17 \times 10^{-8}$ \\
\hline$D_{\text {TAG-oil,ave }}\left(\mathrm{m}^{2} \mathrm{~s}^{-1}\right)$ & $1.16 \times 10^{-10}$ & $5.81 \times 10^{-10}$ & $9.54 \times 10^{-11}$ & $4.71 \times 10^{-10}$ \\
\hline$x_{\mathrm{C} 18: 2}(\% \mathrm{~mol})$ & 40.5 & 33.9 & 40.8 & 35.7 \\
\hline$x_{C 18: 1}(\% \mathrm{~mol})$ & 21.6 & 32.0 & 21.4 & 30.5 \\
\hline$x_{C 18: 0}(\% \mathrm{~mol})$ & 37.8 & 32.1 & 37.8 & 33.9 \\
\hline$X_{f}^{\mathrm{a}}(\%)$ & 31.5 & 32.1 & 31.4 & 32.1 \\
\hline$z_{f}(\mathrm{~mm})$ & 862 & 520 & 1254 & 562 \\
\hline
\end{tabular}

a The small variation of $X_{f}$ is due to different dissolved hydrogen content in the liquid (different concentration fields) at $z_{f}$.
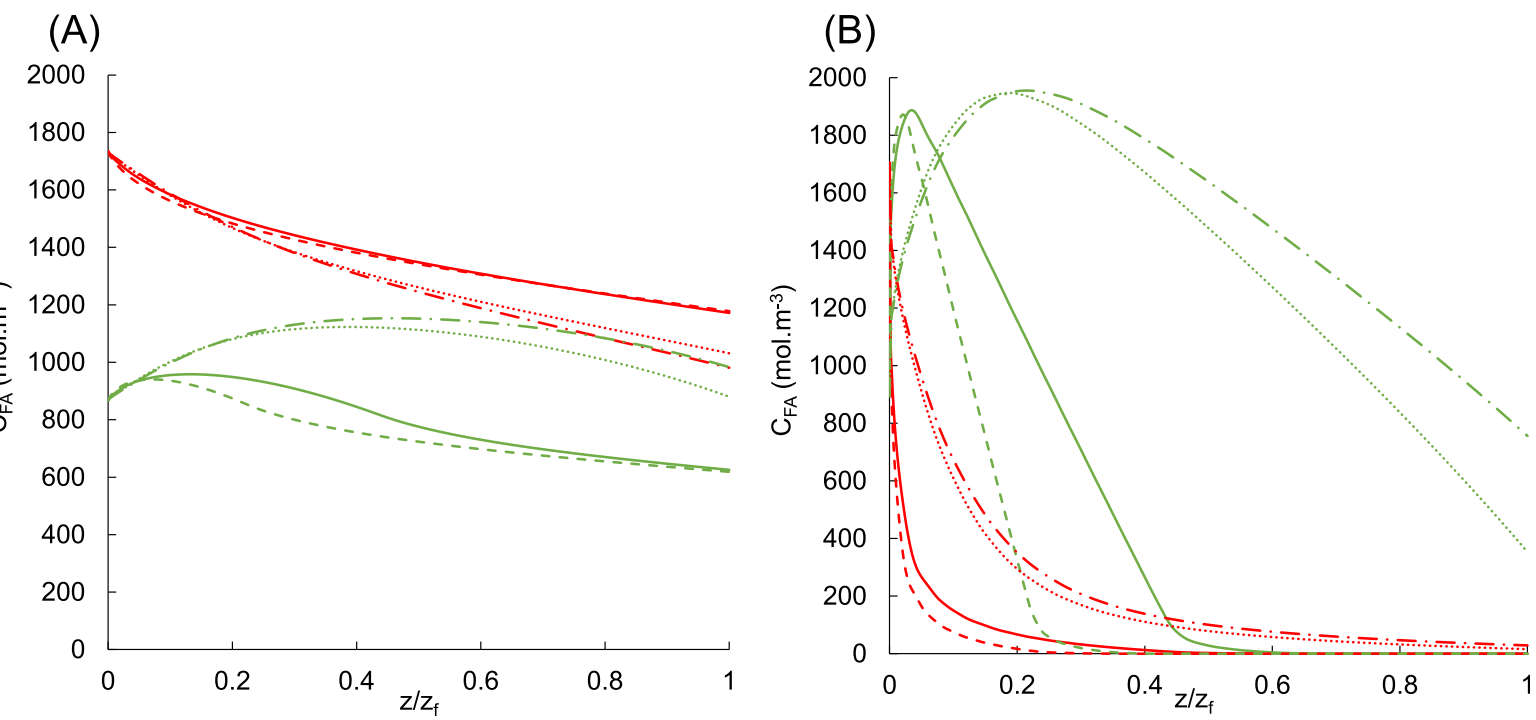

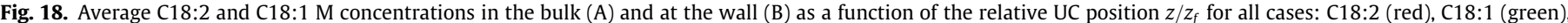

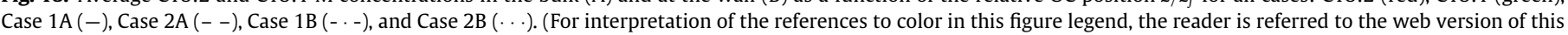
article.)

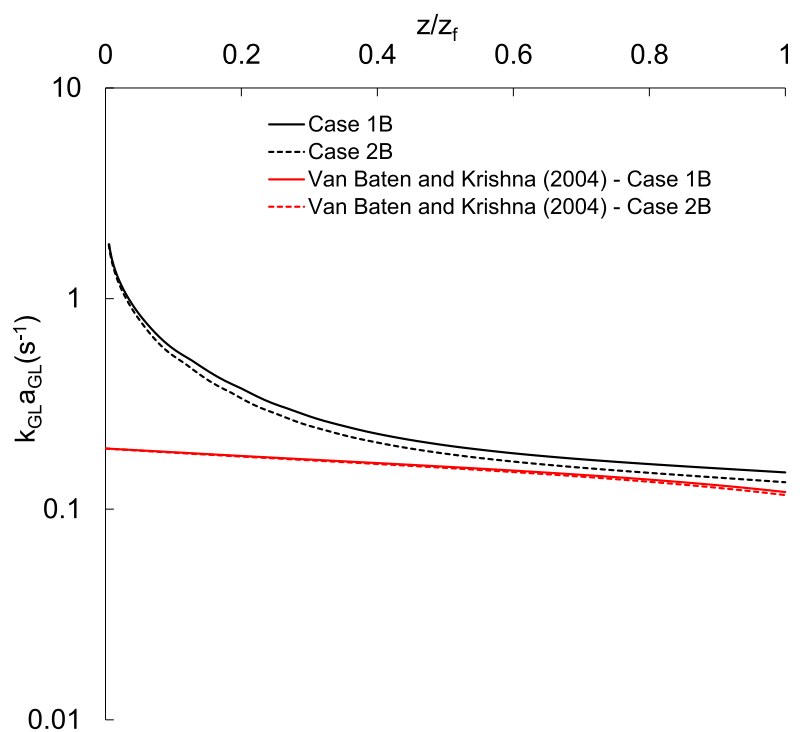

Fig. 19. Gas-liquid mass transfer coefficient $k_{G L} a_{G L}$ in Cases $1 \mathrm{~B}$ and $2 \mathrm{~B}$ calculated using Eq. (42) and estimated with the correlation of van Baten and Krishna (2004).

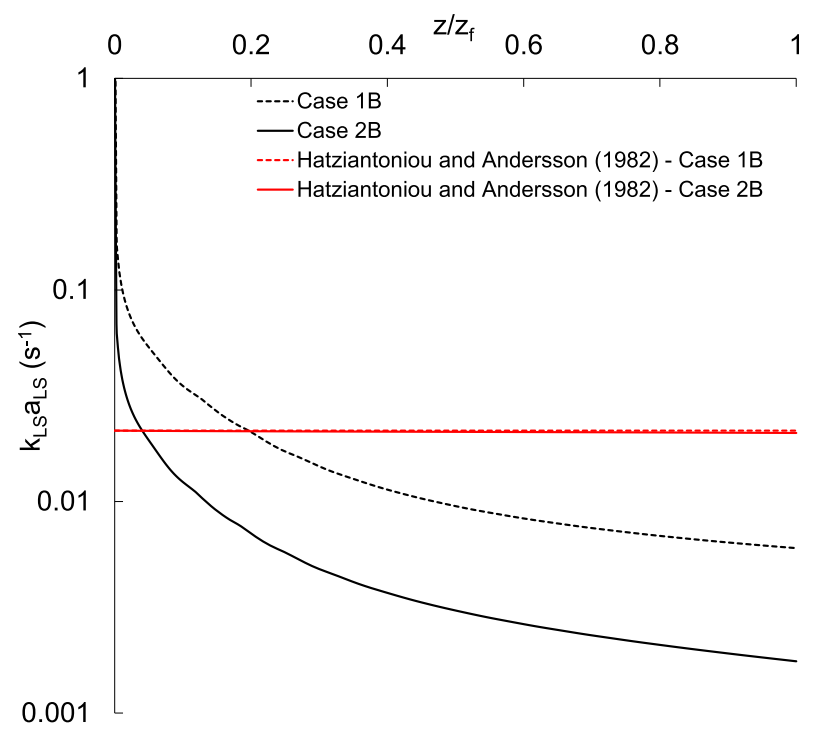

Fig. 20. Liquid-solid mass transfer coefficient $k_{L S} a_{L S}$ for Cases $1 \mathrm{~B}$ and $2 \mathrm{~B}$ calculated using Eq. (43) and estimated with the correlation of Hatziantoniou and Andersson (1982). 


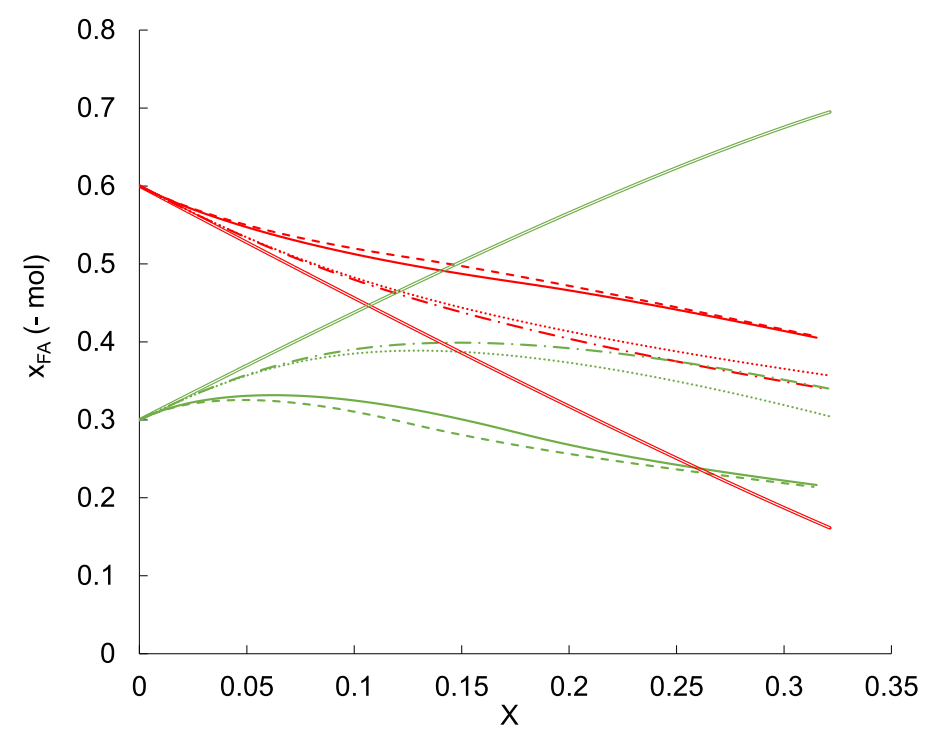

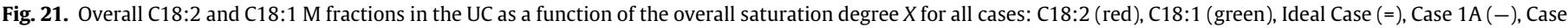
$2 \mathrm{~A}(--)$, Case $1 \mathrm{~B}(-\cdot)$, and Case $2 \mathrm{~B}(\cdots)$. (For interpretation of the references to color in this figure legend, the reader is referred to the web version of this article.)

concentrations of TAG and $\mathrm{H}_{2}$ (taken at saturation) from the liquid bulk to the wall in each successive unit cell. One should notice that in Cases $1 \mathrm{~A}$ and $2 \mathrm{~A}$, the fatty acid fractions step quickly away from the best values expected from the ideal case. In contrast, Cases 1B and 2B match these values on a longer distance. The mass transfer limitation in TAG at the wall clearly hinders the selectivity of the Taylor flow for this consecutive reaction scheme. The question might arise if these resistances can be ignored in any pilot-scale three-phase reactor, or even for different slurries.

\section{Conclusion and perspectives}

In this work, a new model for predicting edible oil viscosity as a function of its saturation degree was developed and implemented in an edible oil hydrogenation CFD model in a monolith-type hydrogenation reactor. This was used to evaluate the influence of viscosity and diffusivity changes along the catalytic channels. In the case of hydrogenation of edible oils, the diffusivity of triglycerides (TAG) is up to two orders of magnitude lower than that of hydrogen, and the selectivity of monolith reactors clearly appears to decrease compared to the ideal plug flow behavior for the chosen operating conditions. This is explained by considering imperfect mixing within the liquid phase, where concentration gradients are no longer restricted to the vicinity of the catalytic wall where the unsaturated fatty acids are converted. Because the TAG transformation is driven by diffusion limitations, it is paramount to account for viscosity changes due to progressive oil saturation. The general approach in this study can be used to evaluate monolith type reactor performances.

The accuracy of the simulations could be improved by accounting for the evolution of the gas-liquid interface area along the channel due to the bubble reduction through gas consumption. A moving mesh approach for describing this phenomenon is currently being studied.

\section{CRediT authorship contribution statement}

Pierre Albrand: Conceptualization, Data curation, Investigation, Software, Visualization, Writing - original draft. Carine Julcour: Formal analysis, Funding acquisition, Investigation,
Methodology, Project administration, Supervision, Validation, Writing - review \& editing. Vincent Gerbaud: Formal analysis, Methodology, Validation. Anne-Marie Billet: Formal analysis, Funding acquisition, Investigation, Methodology, Supervision, Validation, Project administration, Writing - review \& editing.

\section{Declaration of Competing Interest}

The authors declare that they have no known competing financial interests or personal relationships that could have appeared to influence the work reported in this paper.

\section{Acknowledgment}

The authors wish to thank the Institut de Mécanique des Fluides de Toulouse (IMFT) and the Laboratoire des Fluides Complexes et leurs Réservoirs (LFCR) for their help with viscosity and density measurements.

\section{References}

Abiev, R.S., 2011. Modeling of pressure losses for the slug flow of a gas-liquid mixture in mini- and microchannels. Theor. Found. Chem. Eng. 45 (2), 156. https://doi.org/10.1134/S0040579511020011.

Andersson, B., Berglin, T., 1982. On the theory and use of a new fast-response dissolved hydrogen probe for hydrogen transfer studies. Chem. Eng. J. 24 (2), 201-212 030094678280035X

Andersson, K., Hell, M., Löwendahl, L., Schöőn, N., 1974. Diffusivities of hydrogen and glyceryl trioleate in cottonseed oil at elevated temperature. J. Am. Oil Chem. Soc. 51 (4), 171-173. https://doi.org/10.1007/BF02639732.

Aussillous, P., Quéré, D., 2000. Quick deposition of a fluid on the wall of a tube. Phys. Fluids 12 (10), 2367.

Azian, M.N., Mustafa Kamal, A.A., Panau, F., Ten, W.K., 2001. Viscosity estimation of triacylglycerols and of some vegetable oils, based on their triacylglycerol composition. J. Am. Oil. Chem. Soc. 78 (10), 1001-1005. https://doi.org/10.1007/ s11746-001-0378-9.

Belkacemi, K., Boulmerka, A., Arul, J., Hamoudi, S., 2006. Hydrogenation of vegetable oils with minimum trans and saturated fatty acid formation over a new generation of pd-catalyst. Top. Catal. 37 (2), 113-120. https://doi.org/10.1007/ s11244-006-0012-y.

Belkacemi, K., Boulmerka, A., Hamoudi, S., Arul, J., 2006. Activity and selectivity of novel structured pd-catalysts: kinetics modeling of vegetable oils hydrogenation. Int. J. Chem. Reactor Eng. 3 (1).

Belkacemi, K., Kemache, N., Hamoudi, S., Arul, J., 2007. Hydrogenation of sunflower oil over bimetallic supported catalysts on mesostructured silica material. URL https://www.degruyter.com/view/j/ijcre.2007.5.1/ijcre.2007.5.1.1528/ijcre. 2007.5.1.1528.xml. 
Boger, T., Zieverink, M.M., Kreutzer, M.T., Kapteijn, F., Moulijn, J.A., Addiego, W.P., 2004. Monolithic catalysts as an alternative to slurry systems: hydrogenation of edible oil. Ind. Eng. Chem. Res. 43 (10), 2337-2344.

Boyes, A.P., Chugtai, A., Khan, Z., Raymahasay, S., Sulidis, A.T., Winterbottom, J.M., 1995. The cocurrent downflow contactor (cdc) as a fixed bed and slurry reactor for catalytic hydrogenation. J. Chem. Technol. Biotechnol. 64 (1), 55-65 https:// www.sciencedirect.com/science/article/pii/0009250992850910.

Bretherton, F.P., 1961. The motion of long bubbles in tubes. J. Fluid Mech. 10 (2), $166-188$.

Butler, C., Cid, E., Billet, A.-M., 2016. Modelling of mass transfer in taylor flow: Investigation with the plif-i technique. Chem. Eng. Res. Des. 115(Part B), 292302, 10th European Congress of Chemical Engineering. http://www. sciencedirect.com/science/article/pii/S0263876216302866.

Carlson, K.M., Curran, L.M., Ratnasari, D., Pittman, A.M., Soares-Filho, B.S., Asner, G. P., Trigg, S.N., Gaveau, D.A., Lawrence, D., Rodrigues, H.O., 2012. Committed carbon emissions, deforestation, and community land conversion from oil palm plantation expansion in West Kalimantan, Indonesia. Proc. Nat. Acad. Sci. 109 (19), 7559-7564 http://www.pnas.org/content/109/19/7559.

Ceriani, R., Meirelles, A.J., 2004. Predicting vapor-liquid equilibria of fatty systems. Fluid Phase Equilib. 215 (2), 227-236 http://www.sciencedirect.com/science/ article/pii/S0378381203004163.

Ceriani, R., Gonçalves, C.B., Rabelo, J., Caruso, M., Cunha, A.C.C., Cavaleri, F.W. Batista, E.A.C., Meirelles, A.J.A., 2007. Group contribution model for predicting viscosity of fatty compounds. J. Chem. Eng. Data 52 (3), 965-972. https://doi. org/10.1021/je600552b.

Coupland, J.N., McClements, D.J., 1997. Physical properties of liquid edible oils. J. Am. Oil. Chem. Soc. 74 (12), 1559-1564. https://doi.org/10.1007/s11746-9970077-1.

Díaz-Tovar, C.-A., Gani, R., Sarup, B., 2011. Lipid technology: Property prediction and process design/analysis in the edible oil and biodiesel industries. Fluid Phase Equilibria 302 (1-2), 284-293, 12th International Conference on Properties and Phase Equilibria for Product and Process Design. http://www.sciencedirect. com/science/article/pii/S0378381210004668.

Durán Martínez, F., 2017. Réacteur-échangeur de type monolith - stratégie de modélisation et description des phénomènes à l' échelle d'un canal catalytique unique. Ph.D. thesis. http://www.theses.fr/s175472.

Durán Martínez, F.L., Julcour, C., Billet, A.-M., Larachi, F., 2016. Modelling and simulations of a monolith reactor for three-phase hydrogenation reactions rules and recommendations for mass transfer analysis. Catal. Today 273 (Complete), 121-130.

Dutt, N.V.K., Prasad, D.H.L., 1989. Inter-relationships among the properties of fatty oils. J. Am. Oil. Chem. Soc. 66 (5), 701-703. https://doi.org/10.1007/BF02669956.

Eiteman, M.A., Goodrum, J.W., 1994. Density and viscosity of low-molecular weight triglycerides and their mixtures. J. Am. Oil. Chem. Soc. 71 (11), 1261. https://doi. org/10.1007/BF02540548.

Fasina, O.O., Hallman, H., Craig-Schmidt, M., Clements, C., 2006. Predicting temperature-dependence viscosity of vegetable oils from fatty acid composition. J. Am. Oil. Chem. Soc. 83 (10), 899. https://doi.org/10.1007/ s11746-006-5044-8.

Fernández, M.B., Tonetto, G.M., Crapiste, G., Damiani, D.E., 2007. Kinetics of the hydrogenation of sunflower oil over alumina supported palladium catalyst. Int. J. Chem. Reactor Eng. 5 (1).

Fillion, B., Morsi, B., 2000. Gas-liquid mass-transfer and hydrodynamic parameters in a soybean oil hydrogenation process under industrial conditions. Ind. Eng. Chem. Res. 39 (7), 2157-2168. https://doi.org/10.1021/ie990882e.

Fillion, B., Morsi, B.I., Heier, K.R., Machado, R.M., 2002. Kinetics, gas-liquid mass transfer, and modeling of the soybean oil hydrogenation process. Ind. Eng. Chem. Res. 41 (4), 697-709. https://doi.org/10.1021/ie0104013.

Fisher, C.H., 1998. Correlating viscosity with temperature and other properties. J. Am. Oil. Chem. Soc. 75 (10), 1229-1232. https://doi.org/10.1007/s11746-9980167-8.

Fukagata, K., Kasagi, N., Ua-arayaporn, P., Himeno, T., 2007. Numerical simulation of gas-liquid two-phase flow and convective heat transfer in a micro tube. Int. J. Heat Fluid Flow 28(1), 72-82, the International Conference on Heat Transfer and Fluid Flow in Microscale (HTFFM-05). http://www.sciencedirect. com/science/article/pii/S0142727X06001354.

Ganguli, K.L., Berg, H.J.V.D., 1978. Measurements of hydrogen-edible oil interfacial area using a homogeneous ziegler-natta catalyst in an agitated reactor. Chem. Eng. J. 16 (3), 193-197 http://www.sciencedirect.com/science/article/pii/ 0300946778850552.

George, B., Loeser, E., . 2019. Oilseeds: World markets and trade. URL https:/ apps.fas.usda.gov/psdonline/circulars/oilseeds.pdf.

Gunstone, F.D., 2002. Vegetable Oils in Food Technology. John Wiley \& Sons.

Gupta, A., Sharma, S., Toor, A.P., 2007. An empirical correlation in predicting the viscosity of refined vegetable oils. Indian J. Chem. Technol. 14, 642-645.

Gupta, R., Fletcher, D.F., Haynes, B.S., 2009. On the cfd modelling of taylor flow in microchannels. Chem. Eng. Sci. 64 (12), 2941-2950 http://www.sciencedirect. com/science/article/pii/S0009250909001766.

Gupta, R., Fletcher, D., Haynes, B., 2010. Taylor flow in microchannels: a review of experimental and computational work. J. Comput. Multiphase Flows 2 (1), 1-31. https://doi.org/10.1260/1757-482X.2.1.1.

Gut, G., Kosinka, J., Prabucki, A., Schuerch, A., 1979. Kinetics of the liquid-phase hydrogenation and isomerisation of sunflower seed oil with nickel catalysts. Chem. Eng. Sci. 34 (8)

Haase, S., Murzin, D.Y., Salmi, T., 2016. Review on hydrodynamics and mass transfer in minichannel wall reactors with gas-liquid taylor flow. Chem. Eng. Res. Des.
113, 304-329 http://www.sciencedirect.com/science/article/pii/S02638 76216301496.

Hasenhuettl, G.L., 2000. Fats and fatty oils. John Wiley \& Sons, Inc.. https://doi.org/ 10.1002/0471238961.0601201908011905.a01.pub2.

Hatziantoniou, V., Andersson, B., 1982. Solid-liquid mass transfer in segmented gasliquid flow through a capillary. Ind. Eng. Chem. Fundam. 21 (4), 451-456.

Haynes, W.M., 2014. CRC Handbook of Chemistry and Physics. CRC Press.

Hooper, L., Martin, N., Abdelhamid, A., Smith, G.D., jun 2015. Reduction in saturated fat intake for cardiovascular disease. Cochrane Database of Systematic Reviews.

Joglekar, R., Watson, H., 2013. The physical properties of pure triglycerides. J. Indian Inst. Sci. 13, 119.

Kim, J., Kim, D.N., Lee, S.H., Yoo, S.-H., Lee, S., 2010. Correlation of fatty acid composition of vegetable oils with rheological behaviour and oil uptake. Food Chem. 118 (2), 398-402 http://www.sciencedirect.com/science/article/pii/ S0308814609006402.

Koh, L.P., Wilcove, D.S., 2008. Is oil palm agriculture really destroying tropical biodiversity? Conserv. Lett. 1 (2), 60-64 https://onlinelibrary.wiley.com/doi/ abs/10.1111/j.1755-263X.2008.00011.x.

Miller, K., Singh, R., Farkas, B., 1994. Viscosity and heat transfer coefficients for canola, corn, palm, and soybean oil. J. Food Process. Preserv. 18 (6), 461-472. https://doi.org/10.1111/j.1745-4549.1994.tb00268.x.

Mishima, K., Hibiki, T., 1996. Some characteristics of air-water two-phase flow in small diameter vertical tubes. Int. J. Multiph. Flow 22 (4), 703-712.

Morrison, W.H., Robertson, J.A., 1978. Hydrogenated sunflowerseed oil: oxidative stability and polymer formation on heating. J. Am. Oil. Chem. Soc. 55 (5), $451-$ 453. https://doi.org/10.1007/BF02668480.

Mozaffarian, D., Aro, A., Willett, W.C., 2009. Health effects of trans-fatty acids: experimental and observational evidence. Eur. J. Clin. Nutr. 63 (S2), S5S21.

Nielsen, K., Hansen, H.J.M., Nielsen, V.R., 1960. Selectivity in the hydrogenation of oleic-linoleic acid oils with commercial nickel catalysts. J. Am. Oil Chem. Soc. 37 (6), 271-274.

Nirmal, G.M., Leary, T.F., Ramachandran, A., 2019. Mass transfer dynamics in the dissolution of taylor bubbles. Soft Matter 15, 2746-2756. https://doi.org/ 10.1039/C8SM01144C.

Noureddini, H., Teoh, B., Clements, L.D., 1992. Viscosities of vegetable oils and fatty acids. J. Am. Oil Chem. Soc. 69 (12), 1189-1191.

Rabelo, J., Batista, E., Cavaleri, F.v.W., Meirelles, A.J.A., 2000. Viscosity prediction for fatty systems. J. Am. Oil. Chem. Soc. 77 (12), 1255-1262. https://doi.org 10.1007/s11746-000-0197-z.

Ray, J.D., Carr, B.T., 1985. Empirical modeling of soybean oil hydrogenation. J. Am. Oil. Chem. Soc. 62 (8), 1218-1222. https://doi.org/10.1007/BF02541831.

Rhines, P.B., Young, W.R., 1983. How rapidly is a passive scalar mixed within closed streamlines?. J. Fluid Mech. 133, 133-145.

Savchenko, V.I., Makaryan, I.A., 1999. Palladium catalyst for the production of pure margarine. Platin. Met. Rev. 43 (2), 74-82 https://www ingentaconnect.com/content/matthey/pmr/1999/00000043/00000002/art00011.

Schmidt, H.J., 1970. Hydrogenation of triglycerides containing linolenic acids: II Continuous hydrogenation of vegetable oils. J. Am. Oil Chem. Soc. 47 (4), 134 136.

Shao, N., Gavriilidis, A., Angeli, P., 2011. Effect of inlet conditions on taylor bubble length in microchannels. Heat Transf. Eng. 32 (13-14), 1117-1125.

Silva, M.G.D., Singh, R.P., 1995. Viscosity and surface tension of corn oil at frying temperatures. J. Food Process. Preserv. 19 (4), 259-270. https://doi.org/10.1111/ j.1745-4549.1995.tb00293.x.

Snyder, J.M., Dutton, H.J., Scholfield, C.R., 1978. Laboratory-scale continuous hydrogenation. J. Am. Oil. Chem. Soc. 55 (4), 383-386. https://doi.org/ 10.1007/BF02911896.

Thomas, A., Matthäus, B., Fiebig, H.-J., 2000. Fats and Fatty Oils. Wiley VCH Verlag GmbH \& Co..

Timms, R.E., 1985. Physical properties of oils and mixtures of oils. J. Am. Oil. Chem Soc. 62 (2), 241-249. https://doi.org/10.1007/BF02541385.

Topallar, H., Bayrak, Y., Iscan, M., 1995. Effect of hydrogenation on density and viscosity of sunflowerseed oil. J. Am. Oil. Chem. Soc. 72 (12), 1519-1522. https://doi.org/10.1007/BF02577846.

Valeri, D., Meirelles, A.J.A., 1997. Viscosities of fatty acids, triglycerides, and their binary mixtures. J. Am. Oil. Chem. Soc. 74 (10), 1221-1226. https://doi.org 10.1007/s11746-997-0048-6.

van Baten, J., Krishna, R., 2004. Cfd simulations of mass transfer from taylor bubbles rising in circular capillaries. Chem. Eng. Sci. 59 (12), 2535-2545 http:// www.sciencedirect.com/science/article/pii/S0009250904001861.

Veldsink, J.W., Bouma, M.J., Schöön, N.H., Beenackers, A.A., 1997. Heterogeneous hydrogenation of vegetable oils: a literature review. Catal. Rev. 39 (3), 253 318.

Vibrans, F.C., 1935. The solubility of gases in edible fats and oils. Oil Soap 12 (1), 14 15. https://doi.org/10.1007/BF02636584.

Wilke, C.R., Chang, P., 1955. Correlation of diffusion coefficients in dilute solutions AIChE J. 1 (2), 264-270. https://doi.org/10.1002/aic.690010222.

Wolff, J.P., A.K., 2003. Oils and Fats Manual. Springer Verlag GMBH.

Yang, C.-Y., Shieh, C.-C., 2001. Flow pattern of air-water and two-phase r-134a in small circular tubes. Int. J. Multiph. Flow 27 (7), 1163-1177.

Yang L, Nieves-Remacha, MJ. Jensen, K.F, 2017. Simulations and analysis of multiphase transport and reaction in segmented flow microreactors. Chem. Eng. Sci. 169, 106-116.

Young, W., Pumir, A., Pomeau, Y., 1989. Anomalous diffusion of tracer in convection rolls. Phys. Fluids A 1 (3), 462-469. 